\title{
Regional and Local Factors in Attenuation Modelling: Hong Kong Case Study
}

\author{
A.M. Chandler ${ }^{1}$, N.T.K. Lam ${ }^{2}$ and H.H. Tsang ${ }^{3}$ \\ ${ }^{1}$ Professor and Director, Centre for Earthquake Engineering Research (CEER), Department of \\ Civil Engineering, The University of Hong Kong, Pokfulam Road, Hong Kong SAR, China \\ ${ }^{2}$ Associate Professor and Reader, Department of Civil and Environmental Engineering, \\ The University of Melbourne, Parkville, Victoria 3010, Australia (Corresponding Author) \\ Email: n.lam@civenv.unimelb.edu.au Ph: 610383447554 Fax: 610383444616 \\ ${ }^{3}$ Graduate Student, Department of Civil Engineering, The University of Hong Kong, \\ Pokfulam Road, Hong Kong SAR, China
}

\begin{abstract}
Seismic attenuation behaviour is controlled by a large number of wave modification mechanisms. The characteristics of some of these mechanisms are specific to a local area, whilst the remainder can be generalised to the entire seismic region. Factors representing these mechanisms are often not resolved. A new attenuation modelling approach is demonstrated in this paper (using Hong Kong as a case study), to evaluate individual regional and local wave modification factors. Shear wave velocity (SWV) information for the four prevalent geological formations found in Hong Kong was first obtained: a) at shallow depths from instrumented boreholes; b) at depths of up to 100-200 m from measurements using the SPatial Auto-Correlation (SPAC) technique; c) at depths of up to $1.5 \mathrm{~km}$ from the monitoring of quarry blasts; and d) at depths from 1.5 to $8 \mathrm{~km}$ in the hard basement rock layers from results of seismological refraction surveys. The upper-crust amplification factor calculated from the four modelled rock SWV profiles was then combined with predicted attenuation parameters to determine the upper-crust modification factor (filter function) incorporating the local wave modification characteristics associated with Hong Kong geological formations. Such functions may then be combined with the regional attenuation characteristics in that part of the South China region. A seismic attenuation model was developed by combining the upper-crust modification factor with the regional source function of intra-plate earthquakes, based on stochastic simulations. The ground shaking model developed from the presented methodology is supported by the comparison with macro-seismic data of seven historical earthquake events affecting Hong Kong.
\end{abstract}

Keywords: 


\section{Introduction}

Seismic hazard assessment requires a representative ground shaking attenuation relationship to be developed. Attenuation relationships provide predictions for the intensity of ground shaking for any given earthquake scenario, expressed principally in terms of a combination of earthquake magnitude $(M)$ and source-site distance $(R)$.

The attenuation behaviour of earthquake ground shaking is highly complex, but can be approximated by a series of "filters", each of which represents a seismic wave generation, or modification, mechanism along its entire transmission path between the source and the site. The properties of these filters can be generalised to a region, an area or a site depending on the considered mechanism and the method of modelling. Thus, attenuation factors can be classified into (i) regional factors, (ii) area factors (local factors) and (iii) site factors. A recent study by Tsang and Chandler (2005) gives an example of how such a division of attenuation factors can be useful in conducting area-specific and event-specific seismic hazard assessment, especially in regions like South China (including Hong Kong) having large spatial variations in seismic activity rates and in the regional and local attenuation characteristics.

Regional factors characterise the seismic wave generation and transmission mechanisms that can be generalised to the whole region, and comprise the following: (i) source factors (representing properties of seismic waves generated at the source of the earthquake); (ii) geometrical attenuation factors (representing the spatial spread of the radiated seismic energy); and (iii) whole path attenuation factors (representing the dissipation of energy along the wave transmission path before the seismic waves reach the "upper crust", comprising approximately the upper $4 \mathrm{~km}$ of the earth's crust). Local factors characterise the extent of 
amplification and attenuation (energy dissipation) mechanisms in the upper crust. Site factors characterise the filtering mechanisms within the soil sedimentary layers overlying bedrock, which operate on much smaller distance scales.

Despite distinctions between the three tiers of mechanism, their effects have seldom been resolved in existing attenuation models. In regions of high seismicity such as California where strong motion records are abundant, attenuation relationships are developed typically by regression of recorded ground shaking parameters (e.g. Sadigh et al., 1997). In this conventional modelling approach, regional and local factors contributing to the attenuation behaviour of the ground motion are not parameterised separately and are incorporated collectively into an attenuation relationship expressed as a function of magnitude, source-site distance and site classification. Consequently, "local" conditions (as distinguished from "site" conditions) within the region have not been parameterised.

In the absence of recorded strong motion data in regions of low to moderate seismicity, historical seismic intensity (MMI) data presented in the form of iso-seismal contour maps has typically been used to develop intensity attenuation relationships. The development of such relationships requires well-documented archives of historical earthquake events spanning a long period of time, in order that regions possessing different conditions are represented in the database. In Australia, for example, the available records only permit attenuation relationships to be developed for broad sub-regions, namely Western Australia, South-eastern Australia and North-eastern Australia (Gaull et al., 1990). Data are limited to a few major historical events clustered in certain locations. As for other attenuation relationships, intraregional (local) variations have not been parameterised. 
Seismic hazard modelling may alternatively be based on ground motions simulated stochastically in accordance with the seismological model, which characterises earthquake properties by their frequency content. Importantly, the various regional and local mechanisms identified above are represented by separate source and path factors within such a model. Refer to Section 2 for an overview of the seismological model and the listing of its factors.

Numerous seismological models have been developed for the stable continental region (SCR) of Central and Eastern North America (CENA), as reviewed by Atkinson and Boore (1998). Crustal factors can be very significant but there exists relatively little crustal amplification, or attenuation, in CENA because hard rock conditions in the ancient (Archean) rock formations of that region are characterised by very shallow SWV gradients. It is noted that crustal conditions in SCR's around the world can be very different to the conditions in CENA. For example, the eastern part of Australia (east of the Flinder's Ranges) is covered by much younger rock formations than most of Western and Central Australia, or CENA, even though the Australian continent is wholly a SCR. Furthermore, there could be significant variations within a region.

The concept of employing separate factors in the seismological model to represent regional and local mechanisms constituting the earthquake process is logical, and gives the model transparency. In the Hong Kong case study presented in this paper, the generic source factor for intra-plate earthquakes has been combined with regional attenuation factors identified for South China (refer Section 3). These regional factors have then been combined with local crustal factors based on the SWV profile developed specifically for each geological formation, to complete a regional average seismological model for Hong Kong (refer Sections 4-6). Response spectra for rock outcrops obtained by stochastic simulations of the developed seismological model have then been obtained (refer Section 7). 
The objective of presenting the Hong Kong case study in this paper is to stimulate a wider application of the modelling methodology to different areas around the world, and to explore alternative means of evaluating parameters to construct representative seismological models for a diversity of conditions.

The proposed methodology has been based on stochastic simulations and hence is subject to the usual limitations of not modelling azimuth and directivity effects in near-fault conditions. Such limitations are considered not to be important in SCR's, given that specific details of the potential fault source and wave paths are usually very limited and are insufficient for accurate modelling of such effects. Basin edge effects have similarly not been modelled herein. Despite these limitations, stochastic methods have been found to provide a reasonable representation of seismic hazard, according to the review by Atkinson and Somerville (1994). At the end of this paper (Section 7), ground shaking parameters have been compared with the same inferred from MMI data of historical earthquakes, in order to indicate their broad agreement.

Site filtering mechanisms occurring within soil sedimentary layers overlying bedrock are normally taken into account by site factors in codes of practice. Alternatively, onedimensional non-linear shear wave analyses (by programs such as SHAKE developed by Schnabel et al., 1972) have been used as a popular engineering tool in modelling site effects including that of multiple-wave reflections within the soil layers causing conditions pertaining to resonance behaviour. The modelling of site modification factors (filters) is beyond the scope of this paper, but has been dealt with extensively elsewhere (Kramer, 1996). 


\section{Overview of Seismological Model}

In the seismological model, the Fourier amplitude spectrum $A_{X}(f)$ of seismic waves reaching the exposed surfaces of bedrock may be expressed as the product of a number of regional and local factors, as defined by Eq. (1):

$$
A_{X}(f)=S(f) G \operatorname{An}(f) \operatorname{Va}(f) P(f)
$$

where $S(f)$ is the regional, and generic, source factor, $G$ the regional geometric attenuation factor, $\operatorname{An}(f)$ the regional anelastic whole path attenuation factor, $\operatorname{Va}(f)$ the local upper crust amplification factor, and $P(f)$ the local upper crust attenuation factor.

Regional, and generic, source factors have been used to generalise the average behaviour of seismic waves generated at the source of the earthquake to the whole region. For example, the generic source factor of intra-plate earthquakes as developed by Atkinson (1993) has been used to represent conditions in the whole of CENA. The same source factor has been adopted to represent conditions in other intra-plate regions including South China (Lam et al., 2002) and Australia (Lam et al., 2003). Other regional factors represent geometrical attenuation (which is a function of the thickness of the earth's crust) and whole path attenuation (energy absorption along the wave-transmission path, parameterised by the rock Quality or $Q$-factor representative of the region). Modelling of regional factors for the south China region surrounding Hong Kong is described in detail in Section 3.

Upper crustal amplification and attenuation mechanisms occurring in approximately the upper $4 \mathrm{~km}$ of the earth's crust can be considered as local mechanisms and hence are represented by local factors. The study of near-field earthquakes by Abercrombie (1997) based on instrumentation of deep drill-holes in California identified that filtering mechanisms 
occurring within this depth range accounted for some $90 \%$ of the total modifications occurring in seismic waves along their wave-transmission path within the rock crust. In theory, an area with dimensions in the order of $5 \mathrm{~km}$ can be identified with its own local factors (although this is rarely, if ever, done in practice). In practice, attenuation factors are often used to represent much broader areas based on averaging the conditions within the region.

Modelling upper crustal effects requires information on the crustal velocity profile to depths of several kilometres (where seismic waves are generated). SWV information of the rock crust cannot be obtained as easily as compression wave velocities (PWV) from seismological refraction surveys. Despite this, a modelled SWV profile for the generic "Rock" conditions of California was developed by Boore and Joyner (1997), abbreviated herein as BJ97. The development of the model made use of SWV information obtained from some 57 instrumented boreholes in rock together with deep drill-holes reaching depths of between 1 and $3 \mathrm{~km}$. The SWV model conforms to a power-law, and satisfies constraints inferred from borehole measurements taken at shallow depths and from PWV measurements taken at $4 \mathrm{~km}$ depth. This modelled SWV profile has been used in the determination of crustal factors forming part of the seismological model for Californian conditions (Atkinson and Silva, 1997; Atkinson and Boore, 1998). The seismological model so obtained was incorporated into ground motion simulations and response spectrum modelling.

This paper, which describes a methodology comparable to that of BJ97 for seismic attenuation modelling in the vicinity of the southeast Asian city of Hong Kong, demonstrates the use of information from a combination of sources to constrain the model SWV profiles for four principal geological formations that are prevalent in Hong Kong: (i) granitic rock; (ii) volcanic rock; (iii) heavily-jointed volcanic rock, and (iv) meta-sedimentary rock. The meta- 
sedimentary rock in Hong Kong consists of deep deposits ( 900 m) of meta-siltstone (schist), underlain by marble. Separate crustal factors have been obtained for each of these local geological formations. This study has the unique feature of focusing on the modelling of the intra-regional variations in the SWV profile in bedrock (which affects the attenuation behaviour of seismic waves). Furthermore, the manner in which the SWV data was obtained is significantly different to that described in the BJ97 study. An important element in the SWV profiling is the use of micro-tremor monitoring by an array of seven geophones in conjunction with the innovative SPatial Auto-Correlation (SPAC) method, which is an inexpensive, and non-intrusive, way of obtaining rock SWV information to rock depths of some 100-200 m. Detailed coverage of the SWV profiling for the various common geological formations in Hong Kong are presented in Section 4. The SWV information so obtained has been combined with information on the attenuation properties of the earth's crust at both regional and local levels to develop representative local factors for each of the geological formations. The modelling of the upper crustal amplification and attenuation factors are described in Section 5.

\section{Determination of Regional Factors for South China}

\subsection{Source factor $S(f)$ and mid-crust factor $\gamma_{m c}$}

The generic source factor $S(f)$ (for displacement amplitude) defining the Fourier spectrum of the seismic shear waves generated at the source of the earthquake is of the form proposed originally by Atkinson (1993), as given in Eqs. (2) and (3):

$$
S(f)=C M_{0}\left\{(1-\varepsilon) S_{\mathrm{A}}+\varepsilon S_{\mathrm{B}}\right\}
$$

where

$$
\begin{aligned}
& S_{\mathrm{A}}=1 /\left[1+\left(f / f_{\mathrm{A}}\right)^{2}\right] \\
& S_{\mathrm{B}}=1 /\left[1+\left(f / f_{\mathrm{B}}\right)^{2}\right] \\
& C=R_{\mathrm{p}} F V / 4 \pi \rho \beta^{3}
\end{aligned}
$$


$M_{0}$ is the seismic moment, $R_{\mathrm{p}}$ the wave radiation factor, $F$ the free surface amplification factor, $V$ the factor partitioning energy in the two orthogonal directions [the product $R_{\mathrm{p}} F V$ has been taken as 0.78 (Lam et al., 2000c)], $\rho$ the density of the rock at the depth of rupture and $\beta$ the SWV of the rock at the depth of rupture. The intra-plate source model of Atkinson (1993) was based on the generic hard rock conditions of CENA with $\rho=2.8$ tonne $/ \mathrm{m}^{3}$ and $\beta=3.8$ $\mathrm{km} / \mathrm{sec}$ at a depth of approximately $12 \mathrm{~km}$. Refer Atkinson and Silva (1997) and more recent reviews (Atkinson and Boore, 1998; Lam et al., 2000a).

The magnitude-dependent corner frequencies $f_{\mathrm{A}}, f_{\mathrm{B}}$ and the proportioning factor $\varepsilon$ of the adopted intra-plate source model of Atkinson (1993), also termed the CENA source model, are listed as follows:

$$
\begin{aligned}
& \log f_{\mathrm{A}}=2.41-0.533 M \\
& \log f_{\mathrm{B}}=1.43-0.188 M \\
& \log \varepsilon=2.52-0.637 M \\
& \text { where } M \text { is the moment magnitude which has also been denoted as } M_{w} \text {. }
\end{aligned}
$$

The source model expressed in the form of the Fourier spectrum of acceleration amplitude has been presented in Fig. 1, which shows the dependence of the source frequency content on the moment magnitude of the earthquake.

The amplitude of $S$-waves generated from the source of the earthquake is inversely proportional to the SWV of the surrounding crust raised to a power of 3, according to Eq. (2d). Adjustments to allow for other parameter values can be made through the mid-crust modification factor, defined as: 


$$
\gamma_{m c}=\left(\frac{3.8}{V_{s, 8}}\right)^{3}\left(\frac{2.8}{\rho_{8}}\right)
$$

where $V_{s, 8}$ and $\rho_{8}$ is the SWV and crustal density respectively at $8 \mathrm{~km}$ depth.

Shallow earthquakes with centroid of the fault rupture located within the depth range of 5-8 $\mathrm{km}$ have been estimated to have $\rho=2.8$ tonne $/ \mathrm{m}^{3}$ and $\beta=3.5 \mathrm{~km} / \mathrm{sec}$, which are consistent with values estimated from the CRUST2.0 tiles (Global Crustal Model, 2001) surrounding Hong Kong [refer Section 4.3 and Eq. (11b)]. The mid-crust modification factor has accordingly been taken equal to 1.3 .

The source factor described herein was used originally to model ground motion properties in CENA (Atkinson, 1993), and has subsequently been extended to ground motion modelling in Australia (Lam et al., 2003), South China (Lam et al., 1999; 2002; Chandler and Lam, 2002), Singapore (Balendra et al., 2002) and the distant effects of Gujarat earthquake in India (Chandler and Lam, 2004). The good agreement of the modelled ground motions with records and field observations from historic and recent earthquake events occurring in these regions support the generalisation of the model to all SCR's of low to moderate seismicity, including the South China region surrounding Hong Kong.

\subsection{Regional geometrical attenuation factor $G$ for South China}

The Geometrical $(G)$ factor represents the attenuation of the amplitude of the radiated seismic waves resulting purely from the geometrical spread of energy (as opposed to dissipation of energy). The $G$ factor in the near-field conforms to spherical attenuation and is independent of regional conditions [refer Eq. (5a)]. The $G$ factor becomes regionally dependent in the farfield where the attenuation pattern is influenced significantly by seismic waves reflected from the Moho discontinuity, which defines the interface between the earth's crust and the 
underlying lithosphere. The significance of the Moho reflection increases with decreasing thickness of the earth's crust, according to Eqs. (5b) and (5c). This attenuation model was developed originally from seismological observations (Atkinson and Mereu, 1992) and was confirmed more recently in Chandler and Lam (2004) in which the recorded attenuation of ground shaking at long distances from recent major earthquake events were compared to ground motions simulated in accordance with the seismological model.

$$
\begin{aligned}
& G(R, D)=\frac{30}{R}(\text { for } R \leq 1.5 D) \\
& G(R, D)=\frac{30}{1.5 D}(\text { for } 1.5 D<R \leq 2.5 D) \\
& G(R, D)=\frac{30}{1.5 D} \cdot \sqrt{\frac{2.5 D}{R}}(\text { for } R>2.5 D)
\end{aligned}
$$

where $R$ is the source-site distance of the earthquake and $D$ is the crustal thickness.

The value of $D$ for the South China region has been identified using data from CRUST2.0 to be $30 \mathrm{~km}$, which is consistent with the assumption of Lam et al. (2002).

\subsection{Regional whole path anelastic attenuation factor An(f) for South China}

Whole path attenuation is particularly important in the modelling of ground shaking from distant earthquakes (Chandler and Lam, 2004). Large-magnitude earthquakes generated at source-site distance $(R)$ exceeding $100 \mathrm{~km}$ are typified by low-frequency (long-period) seismic waves, since the high-frequency components have greatly diminished in amplitude as a result of energy absorption along the source-site wave travel path. The peak ground acceleration (PGA) from such distant earthquakes can be very low and yet the induced motion can be disproportionately destructive due to its high displacement and velocity shaking characteristics, which result from medium- and long-period waves that are relatively robust to crustal attenuation. 
Whole path attenuation is a regional mechanism and must be distinguished from local attenuation of the upper crust or site attenuation within the overlying soil medium. The attenuation mechanism may be characterized by the value of the seismological quality factor $Q$ (equivalent to $Q_{0}$, namely $Q$ at frequency of $1 \mathrm{~Hz}$ ) as obtained from seismological monitoring in the region. The value of $Q$ may be substituted into Eq. (6) to develop the filter function $A n(f)$ representing the effects of whole path attenuation of seismic waves propagating within the earth's crust:

$$
A n(f)=e^{-\frac{\pi \cdot f \cdot R}{Q \cdot V_{s}}}
$$

where $f$ is the wave frequency, $R$ is the length of the wave travel path and $V_{s}$ is the SWV.

The $Q(f)$ function is then defined by:

$$
Q(f)=Q_{0} f^{\eta}
$$

Substitution of Eq. (7) into Eq. (6) yields the estimated whole path attenuation factor.

Mak et al. (2004) determined the $Q$ factor for the part of the South China region surrounding Hong Kong, using the single backscattering model of coda wave attenuation proposed by Aki (1969) and Aki and Chouet (1975). The former study employed data from 25 local earthquakes, within $200 \mathrm{~km}$ of Hong Kong, digitally recorded from January 1998 to July 2000 by eight short-period stations of the Hong Kong Observatory seismic monitoring network. By analyzing the coda wave at frequencies $2-20 \mathrm{~Hz}$, a median $Q-f$ relation of $Q=$ $256 f^{0.7}$ has been obtained, for the region within $200 \mathrm{~km}$ of Hong Kong. The results are consistent with $Q$ factors reported for the wider region of South China in earlier studies (Jin and Aki, 1988; Chen and Nuttli, 1984; Wong et al., 2002). For more distant earthquakes in South China affecting Hong Kong, Mak et al. (2004) recommend somewhat higher values of 
whole path $Q_{0}$ (in the range 350-500) should be adopted, especially for studies involving distant scenario earthquake events (M-R combinations).

Substituting a representative $Q_{0}$ value of 256 into Eqs. (10)-(11) yields the frequencydependent whole path attenuation function, which may then be combined with local upper crustal amplification and attenuation factors, as described below. Such a regional $A n(f)$ function, representing the whole path attenuation filter, has been presented graphically in Fig. 2 for distances $R$ varying between $30 \mathrm{~km}$ and $300 \mathrm{~km}$, in order to ascertain its relative degree of significance.

\section{SWV Profiling for Common Geological Formations in Hong Kong}

The upper crustal amplification and attenuation mechanisms occur locally within some $4 \mathrm{~km}$ from the site (of the recorder). Upwardly propagating $S$-waves are amplified when the waves cross from one medium to a lower velocity medium and can be explained by the principle of conservation of energy. Upper-crust amplification is a function of the SWV profile (its value and gradient) in the earth's crust, particularly at shallow depths and is period (or frequency) dependent. Co-existing with the amplification mechanism in the upper crust is the upper crustal attenuation mechanism. To develop representative local factors representing these two mechanisms, the SWV profile for each of the common geological formations in Hong Kong must first be established.

\subsection{Shear Wave Velocity (SWV) profiling from engineering borehole data}

Four principal types of measured SWV data are available for Hong Kong. The first comprises very extensive engineering borehole data for soil and reclamation sites throughout the 
territory, for which SWV data for the upper 10-15 m of the underlying bedrock is frequently obtained. Such data have been divided according to the main geological formations prevalent in Hong Kong, which comprise granitic, volcanic, heavily-jointed volcanic and metasedimentary rocks, and have been plotted in Figs. 3(a)-(d), respectively.

Ground investigation information for Hong Kong has been compiled from three main sources: (i) the Geotechnical Information Unit (GIU) of the Geotechnical Engineering Office (GEO), HKSAR; (ii) Ove Arup and Partners (Hong Kong) Limited (e.g. Arup, 1999); and (iii) ground investigation contractors databases (e.g. EGS, 2001; Halcrow, 1999). This ground investigation database covers all principal built-up areas in Hong Kong, and by inference the resulting SWV profile is considered representative of the entire Hong Kong region. A large proportion of the ground investigation borehole logs provide standard penetration test (SPT) results. Empirical correlation relationships between SPT N-value and SWV for Hong Kong (Chandler and Su, 2000) have then been used to estimate the SWV for each set of borehole data.

SWV testing is not commonly carried out in Hong Kong for general ground investigation purposes and therefore the number of SWV profiles is limited. Yet, some SWV measurements have been carried out using a range of techniques: (i) crosshole (e.g. EGS, 1998); (ii) downhole; (iii) suspension PS logging; (iv) refraction; and (v) spectral analysis of surface waves (e.g. Wong et al., 1998).

In order to obtain the value of SWV at a reference depth of $30 \mathrm{~m}(0.03 \mathrm{~km})$, termed $V_{s, 30}$, the following formula is proposed (Chandler et al., 2005a):

$$
\sum\left[\log \left(V_{s, i}\left(Z_{i}\right)\right)-\log \left(V_{s}\left(Z_{i}\right)\right)\right]=0 \quad \text { where } V_{s}(Z)=V_{s, 30}\left(\frac{Z}{30}\right)^{\frac{1}{4}}
$$


where $V_{s, i}\left(Z_{i}\right)$ is the shear wave velocity at the depth $Z_{i}$.

Eq. (8) was used in regression analyses to determine representative values of $V_{s, 30}\left(V_{s, 6}\right.$ in the case of meta-sedimentary rock) for various geological formations that are prevalent in Hong Kong. Results are summarised below, in Eqs. (9a)-(9e):

Granitic formation:

$$
V_{s}(Z)=1350\left(\frac{Z}{30}\right)^{\frac{1}{4}} \quad Z<120 m
$$

Volcanic formation:

$$
V_{s}(Z)=2200\left(\frac{Z}{30}\right)^{\frac{1}{4}} \quad Z<32 m
$$

Heavily-Jointed Volcanic formation: $V_{s}(Z)=1600\left(\frac{Z}{30}\right)^{\frac{1}{4}} \quad Z<48 m$

Meta-Sedimentary formation:

$$
V_{s}(Z)=1150\left(\frac{Z}{6}\right)^{\frac{1}{4}} \quad Z<6 m
$$

Regional Average:

$$
V_{s}(Z)=1700\left(\frac{Z}{30}\right)^{\frac{1}{4}} \quad Z<60 m
$$

As the thickness of weathered rock in Hong Kong is highly variable (hence site-dependent), the depth ranges proposed in Eqs. (9a)-(9e) have been guided by the measured SWV's of the deeper unweathered rock layers (refer Section 4.2). In other words, the assumed depth value (for a given geological formation) actually represents the intersection between the weathered layer and the underlying unweathered layer. It is noted that, in addition to the four prevalent geological formations, a regional average profile for Hong Kong has also been proposed. The latter may be used in a regional study, or to make comparisons with historical seismic intensity (MMI) data, considered representative of the entire Hong Kong region (refer Section 7). The regional average profile has been determined by assigning an appropriate set of weightings to different geological formations in Hong Kong (based mainly on their 
relative frequency of occurrence in the Territory). The assumed weightings are $0.4,0.35,0.2$ and 0.05 , for granitic, volcanic, heavily-jointed volcanic and meta-sedimentary rocks, respectively.

\subsection{Shear Wave Velocity profiling from SPAC surveys and monitoring of quarry blasts}

The second type of measured SWV data has been obtained from the innovative SPatial AutoCorrelation (SPAC) surveys (Aki, 1957; Asten et al., 2002; Roberts et al., 2004; Lam et al., 2004). This method is inexpensive and non-intrusive, and provides accurate SWV measurements to depths of 100-200 m.

In October 2004, detailed SPAC surveys were conducted at five sites in Hong Kong, comprising two on granitic rock, two on volcanic rock and one on meta-sedimentary rock. Details of the SPAC surveys have been provided in Appendix A. The measured SWV data from different sites in Hong Kong was originally published in Tsang et al. (2005) and is reproduced in Fig. 4.

The third type of measured SWV data has been obtained from a recent study on the upper crustal structure of Hong Kong (Mak, 2005). This study used short-period group velocity (T $=0.4-1.3 \mathrm{sec}$ ) dispersion of $R_{g}$ waves generated by quarry blasts within the city, and has yielded reliable SWV data for the depth range of approximately $200 \mathrm{~m}$ to $1500 \mathrm{~m}(1.5 \mathrm{~km})$, as shown in Figs. 5(a) and 5(b). In this depth range, rock units are primarily igneous and are free from weathering. There is a widespread presence (throughout Hong Kong) of a layer with near-constant SWV in the order of $2 \mathrm{~km} / \mathrm{s}$. This rock layer is underlain by a much harder basement rock with significantly higher SWV, as indicated by the velocity discontinuity at depth of around $1.5 \mathrm{~km}$. 
The modelled SWV profiles representing the granitic, volcanic, heavily-jointed volcanic and meta-sedimentary rocks, and the representative profile for Hong Kong, in the unweathered zone are defined by Eqs. (10a)-(10e), respectively. The velocity of each layer has been determined by incorporating information obtained from seismological surveys employing different techniques. For example, the SWV profile in the uppermost unweathered zone for granitic rock was estimated in accordance with measurements obtained from both the geophone array surveys (with data subject to SPAC analyses) and the blast monitoring survey (with data subject to dispersion analyses). In combining results obtained from the two surveying techniques, a weighing factor of 0.2 was assigned to results derived from each of the two array (SPAC) surveys and 0.3 for each of the two blast monitoring surveys. The blast monitoring surveys were assigned heavier weighing factors in view of the more consistent measurements obtained from the individual surveys. The same weighing factors have been used in the estimation of the regional average SWV profile for Hong Kong.

Granitic formation:

Volcanic formation:

Meta-Sedimentary formation:

Heavily-Jointed Volcanic formation:

$$
\begin{aligned}
& V_{s}(Z)=1820 \mathrm{~m} / \mathrm{s} \\
& V_{s}(Z)=2120 \mathrm{~m} / \mathrm{s}
\end{aligned}
$$$$
V_{s}(Z)=1150 \mathrm{~m} / \mathrm{s}
$$

$$
\begin{aligned}
& V_{s}(Z)=1900 \mathrm{~m} / \mathrm{s} \\
& V_{s}(Z)=2150 \mathrm{~m} / \mathrm{s} \\
& V_{s}(Z)=2160 \mathrm{~m} / \mathrm{s}
\end{aligned}
$$$$
500<Z<1000 \mathrm{~m}
$$$$
1000<Z<1500 \mathrm{~m}
$$

$$
\begin{array}{ll}
V_{s}(Z)=2240 \mathrm{~m} / \mathrm{s} & 32<Z<500 \mathrm{~m} \\
V_{s}(Z)=2390 \mathrm{~m} / \mathrm{s} & 500<Z<1000 \mathrm{~m} \\
V_{s}(Z)=2330 \mathrm{~m} / \mathrm{s} & 1000<Z<1500 \mathrm{~m}
\end{array}
$$




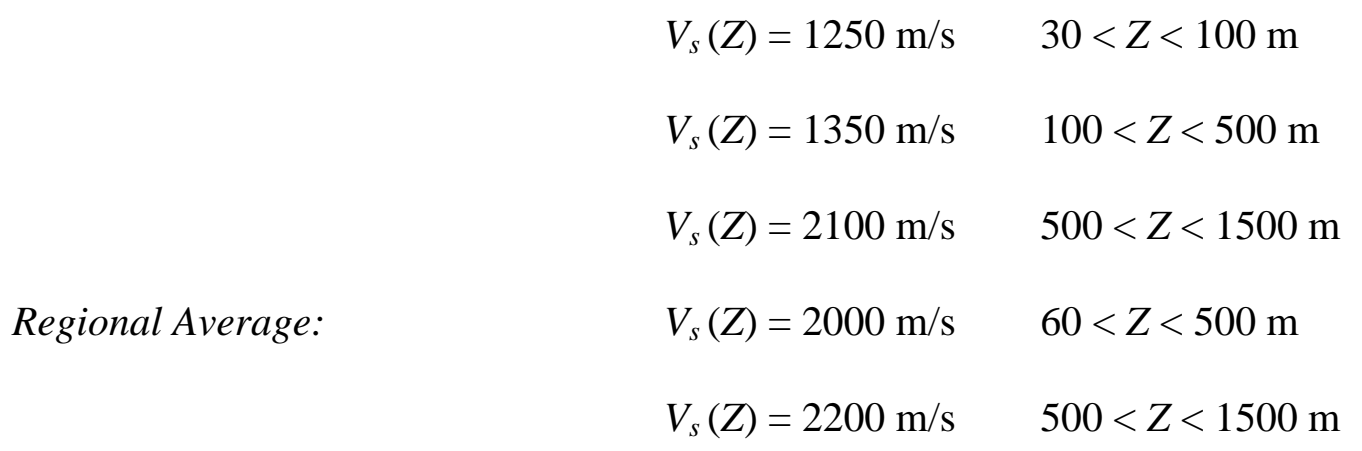

\subsection{Shear Wave Velocity (SWV) profiling from seismic refraction data}

Finally, the regional seismic refraction data available from the web-based Global Crustal Model (2001), also known as CRUST2.0, has been employed to provide estimates for the SWV profile at depths exceeding $1 \mathrm{~km}$. The sixteen $2 \times 2$ degree tiles surrounding Hong Kong in CRUST2.0 indicate a SWV discontinuity at $1.5 \mathrm{~km}$ depth, where the hard crystalline (basement) rock crust interfaces with the overlying granitic/volcanic rock crust, and this is consistent with observations from the monitoring of quarry blasts (Section 4.2). The CRUST2.0 database also indicates SWV of $3.5 \mathrm{~km} / \mathrm{sec}$ at $8 \mathrm{~km}$ depth (refer Fig. 6), consistent with properties identified with generic rock (BJ97) and with assumptions made in previous studies (Lam et al., 2002). This SWV information can be extrapolated upward through the earth's crust according to a suitable power law, with $n=1 / 12$. The $n$ value is changed to $1 / 6$ at $4 \mathrm{~km}$ depth to account for the non-linear correlation between SWV and PWV at shallower depths, according to recommendations by Chandler et al. (2005a), refer Fig. 6. The model profile representing these basement crystalline rock layers is shown in Fig. 6, and is defined by Eqs. (11a) and (11b), respectively.

Upper Crystalline Layer: $\quad V_{s}(Z)=3300\left(\frac{Z}{4000}\right)^{\frac{1}{6}} \quad 1500 m<Z<4000 m$

Lower Crystalline Layer: $\quad V_{s}(Z)=3500\left(\frac{Z}{8000}\right)^{\frac{1}{12}} \quad 4000 m<Z$ 


\subsection{Comparison with generic SWV profile models}

Fig. 7 compares the representative SWV profile (to crustal depths of $8 \mathrm{~km}$ ) derived herein for Hong Kong, with regional profiles for generic rock $(G R)$ and generic hard rock $(G H R)$ (BJ97). It is noted that the regional average Hong Kong SWV profile is similar to that of $G R$, for depths exceeding $1.5 \mathrm{~km}$. However, the presence of the constant-velocity igneous rock layer in the Hong Kong SWV profile implies that, interestingly, Hong Kong is underlain by relatively softer rocks (velocity below that of generic rock) for depths ranging between around $250 \mathrm{~m}$ and $1.5 \mathrm{~km}$, whilst the rock for the upper $250 \mathrm{~m}$ is considerably harder than $G R$. The implications of the SWV profile for the resulting crustal filter functions are discussed below.

\section{Determination of Local Factors}

\subsection{Determination of upper crustal amplification factor for Hong Kong}

The extent of upper-crust amplification may be predicted from Eq. (12), using $\rho_{B}$ and $V_{B}$ to represent the rock density and SWV at the source depth, which is typically assumed as $z=D=8 \mathrm{~km}$ (Chandler et al., 2005a), and $\rho_{A}$ and $V_{A}$ at a depth corresponding to the period of interest.

$$
V\left(V_{s}, \rho\right)=\sqrt{\frac{\rho_{B} V_{B}}{\rho_{A} V_{A}}}
$$

To relate the period of interest to the rock depth, the quarter-wavelength approximation method (Joyner et al., 1981; Boore and Joyner, 1997; BJ97) is required. This method allows the values of $\rho_{A}$ and $V_{A}$ to be averaged to a depth equivalent to the quarter-wavelength of the upwardly propagating $S$-wave, for applying Eq. (12). 
The variation of upper-crust amplification factor $V(f)$ with frequency has been shown in Fig. 8 for the four geological formations commonly found in Hong Kong, and the regional average SWV profile. An increase in the value of $V$ with increasing wave frequency is noted in each case. The slope discontinuity occurring at frequency in the order of $0.3-0.4 \mathrm{~Hz}$ (except meta-sedimentary) arises due to the velocity discontinuity at the bottom of the constant-velocity layer (depth of $1.5 \mathrm{~km}$ ) in the rock profiles for Hong Kong (Fig. 6).

It can be inferred from the BJ97 "quarter-wavelength principle" [refer Eq. (12)] that upper crustal amplification of seismic waves with period components of engineering interest (typically with period less than 5 seconds, implying frequency exceeding $0.2 \mathrm{~Hz}$ ) occurs in the upper $4 \mathrm{~km}$ of the rock crust. The SWV in this depth range is in the order of $2-3 \mathrm{~km} / \mathrm{sec}$ (averaging around $2.5 \mathrm{~km} / \mathrm{s}$ ) according to Fig. 6. Upper crustal attenuation is considered to occur also within this depth range (refer Section 5.2).

\subsection{Determination of upper crustal attenuation factor for Hong Kong}

Wave transmission quality within bedrock is not uniform with depth. Attenuation in the upper crust is a local phenomenon and is represented by a local factor and the mechanism occurs over a short transmission distance, as for attenuation in soft soil sediments. As stated above, Abercrombie (1997) identified that $90 \%$ of the total attenuation of seismic waves in Californian bedrock occurred within the upper 3-4 km of the earth's crust.

The upper crustal attenuation factor, $P(f)$, in the seismological model has been defined by Eq. (13):

$$
P(f)=e^{-. \pi f \kappa}
$$


where the parameter $\kappa$ (in units of seconds and pronounced "Kappa") can be measured from analysis of the Fourier transform of seismic waves recorded from the very near-field (Anderson and Hough, 1984).

The parameter $\kappa$ is generally difficult to measure in regions of low and moderate seismicity because of magnitude or epicentral distance requirements associated with the measurements. When this important mechanism has not been ascertained, a reliable seismological model for the region is difficult to develop. A method for estimating $\kappa$ is to make inferences from the SWV near to the rock surface. An empirical correlation of $\kappa$ with the average SWV $V_{u c}$ of the upper crust (taken as the upper $4 \mathrm{~km}$ depth), has been developed by Chandler et al. (2005b) using global information obtained from limited independent studies. The proposed relationship is as follows:

$$
\kappa=0.145-0.12 \ln \left(V_{u c}\right) \geq 0 \quad\left[V_{u c} \geq 1.6 \mathrm{~km} / \mathrm{s}\right]
$$

where $V_{u c}$ is expressed in units of $\mathrm{km} / \mathrm{sec}$ and $\kappa$ is in sec.

The average SWV $V_{u c}$ of the upper crust was chosen for the purpose of identifying $\kappa$ (for the respective geological formations prevalent in Hong Kong), in view of the fact that the attenuation mechanism represented by this parameter occurs in the upper $4 \mathrm{~km}$ of the earth's crust and hence the inferred $\kappa$ values account explicitly for local variations in the upper crust parameters. The values of $\kappa$ obtained from Eq. (14) for the granitic, volcanic, heavily-jointed volcanic, meta-sedimentary formations and the regional average are, respectively, 0.032, $0.024,0.036,0.040$ and 0.030 (as listed in Table 1). If the same weightings $(0.4,0.35,0.2$ and 0.05, respectively for granitic, volcanic, heavily-jointed volcanic and meta-sedimentary formations) are applied to these $\kappa$ values, a consistent regional average value of 0.030 is obtained. 
The value of $\kappa$ inferred from Eq. (14) for the regional average SWV profile has been verified by another method, that is to take the regional median quality factor for the upper crust $Q_{\mathrm{uc}}$ to be 0.2 times the value of $Q_{0}(=256)$ representing whole path attenuation (Chandler et al., 2005b). Hence, $Q_{\mathrm{uc}}$ is inferred to be in the order of 50 for Hong Kong. The regional average value for $\kappa$ is estimated at 0.030 from Eq. (15) based on $R_{\mathrm{uc}}$ (length of wave path within the upper crust) equal to $4 \mathrm{~km}$ and $V_{\mathrm{uc}}$ equal to $2.62 \mathrm{~km} / \mathrm{s}$ (refer Table 1 ).

$$
\kappa=R_{\mathrm{uc}} /\left(Q_{\mathrm{uc}} V_{\mathrm{uc}}\right)
$$

Each of the variables in Eq. (15) has been assigned the subscript " $u c$ ", which denotes contributions arising in the upper crust.

The frequency dependent upper-crust attenuation factor $P(f)$ as defined by Eq. (13) has been multiplied by the upper-crust amplification factor $V(f)$ derived in Section 5.1, giving the combined factor as shown in Fig. 9, for the four geological formations commonly found in Hong Kong as well as the regional average.

\section{Combined Regional and Local Modification Factors}

The frequency dependent upper-crust attenuation factor $P(f)$ as defined by Eq. (13) [adopting $\kappa=0.030$ ] has been multiplied by the upper-crust amplification factor $V(f)$ derived in Section 3.4, giving the overall modification factor shown by the short-dashed curve in Fig. 10. This upper-crust modification factor (filter function) has been further combined with the mid-crust modification factor $\gamma_{\mathrm{mc}}$ of 1.3 (derived in Section 3.1) and the anelastic whole path attenuation factor $A n(f)$ at $30 \mathrm{~km}$ distance (derived in Section 3.3), as shown by the long-dashed curve and the thick solid curve, respectively. The latter curve 
represents the total (regional and local) filtering effects of the earth's crust along its entire wave transmission path of $30 \mathrm{~km}$.

Fig. 11 compares the upper-crust modification factor representing conditions in the Hong Kong region with that determined in BJ97 for $G R$ and $G H R$ conditions of California and CENA, respectively. It is shown that seismic waves reaching the rock surface in Hong Kong are characterised by significantly larger lower-frequency components $(0.2-2.0 \mathrm{~Hz})$ compared with the higher-frequency components $(f>2.0 \mathrm{~Hz})$. Seismic waves with frequency in the order of $0.3-1.0 \mathrm{~Hz}(1-3$ seconds period) are subject to the highest net amplification of seismic waves (in the order of 1.35), following emission from the earthquake source. The latter finding, which contrasts with the situation for $G R$ (highest net amplification around 1.65 , at frequency in the order of $2 \mathrm{~Hz}$ or 0.5 seconds period) is a finding of engineering importance, especially given the prevalence of tall buildings in Hong Kong with natural periods in the order of 2 seconds or higher. It is further noted that the upper-crust modification factor of Hong Kong for frequency below $0.5 \mathrm{~Hz}$ (above 2 seconds period) is comparable to that of $G R$.

\section{Response Spectrum Modelling and Comparison with Historical MMI Data}

Synthetic accelerograms have been simulated stochastically using the computer program GENQKE (Lam et al., 2000a). The response spectra calculated from 18 accelerograms with random phase angles were averaged for different earthquake scenarios based on a common reference source-site distance of $30 \mathrm{~km}$. Response spectra obtained for $\mathrm{M}=6$ earthquakes have been shown in Fig. 12(a). It is considered that the difference between the response spectra simulated for the four rock types is significant, thereby confirming the importance of the local effect discussed above. Nevertheless, for convenience the response spectra presented in 
Fig. 12(b) for other earthquake scenarios have been based on the regional average SWV profile for Hong Kong.

An attenuation relationship expressed in terms of the notional peak ground velocity (PGV) has further been developed from the simulated response spectra. The PGV was taken as the highest response spectral velocity divided by 1.8 (Wilson and Lam, 2003).

The expression to transform from MMI of the historical records to PGV $(\mathrm{mm} / \mathrm{sec})$ was originally developed by by Newmark and Rosenblueth (1971), but a more elaborate and well known model developed recently by Atkinson and Sonley (2000) based on observations from 29 Californian earthquakes was used for the calculations in this study. The model as represented by Eq. (16) takes into account the effects of magnitude and distance on the MMIPGV correlation.

$$
\log (P G V)=-1.09+0.16 M M I-0.37 \log (D)+0.26 M
$$

where $P G V$ is in units of $\mathrm{cm} / \mathrm{sec} ; D$ is epicentral distance in $\mathrm{km}$ and $M$ is moment magnitude.

Whilst Eq. (16) was originally developed from observations in a high seismic area, predictions using this expression have been found to be very consistent with observations from a recent destructive earthquake in Australia and hence has been used in transforming MMI to PGV for the Victorian region, Australia (Lam et al., 2005). A comparison of MMIPGV relationships by the authors (refer Fig. 1 in Lam et al., 2003) also revealed similarities in the relationship used in China and that recommended by Newmark and Rosenblueth (1971) based on Californian conditions. It is noted that correlations between the two parameters are typically characterised by large scatters. Error by a factor of about $1.8-1.9$ is 
noted in the predictions of PGV for any given value of MMI using Eq. (16) according to Atkinson and Sonley (2000).

Seven historical events in South China, which were felt in the Hong Kong region with MMI of V-VI, have been employed in the comparison (Table 2 and Fig. 13). The magnitude (M) and source-site distance $(R)$ are ranged, respectively, 5.5-8.0 and 30-600 km. In the comparative analyses, the seismological models were based on the regional average $Q_{0}$ value of 256 (refer Section 3.3), except for events with distance $R$ exceeding $200 \mathrm{~km}$. For such events, distance-dependent $Q_{0}$ values based on recommendations of Mak et al. (2004) were used.

The inferred and modelled PGV's differ by a factor in the order of 2 (i.e. one unit of MMI increment), for the entire distance range. The discrepancies can be explained by the fact that the modelled PGV's are based on rock conditions, whereas the PGV's inferred from MMI data refer to average site conditions. This inferred site factor is interestingly consistent with a similar correlation undertaken by the authors in the modelling of Australian earthquakes (Lam et al., 2005). The comparison of the modelled results with macro-seismic data as presented in Table 2 and Fig. 13 offers some support to the methodology presented in this paper.

\section{Conclusions}

(i) The generic source factor of intra-plate earthquakes (as developed by Atkinson) has been adopted for Hong Kong, along with a mid-crust amplification factor of 1.3.

(ii) The geometrical attenuation factor has been based on a regional crustal thickness of 30 $\mathrm{km}$. 
(iii) The anelastic attenuation behaviour has been characterised by a $Q_{0}$ factor for the Hong Kong region (for source-site distances up to $200 \mathrm{~km}$ ) with a median value of 256 . For larger source-site distances up to $600 \mathrm{~km}$ from Hong Kong, representing the South China region, values of $Q_{0}$ in the range 350-500 have been recommended.

(iv) This paper has demonstrated the use of shear wave velocity (SWV) information from a combination of sources to constrain the model SWV profiles for four principal geological formations in Hong Kong: (i) granitic formation, (ii) volcanic formation, (iii) heavily-jointed volcanic formation, and (iv) meta-sedimentary formation. SWV information for each of these common geological formations were obtained as follows: a) at shallow depths from instrumented boreholes; b) at depths of up to 100-500 m from SPAC measurements; c) at depths up to $1.5 \mathrm{~km}$ from the monitoring of quarry blasts; and d) at depths $1.5-8 \mathrm{~km}$ in the hard (crystalline) basement rock layers from results of seismological refraction surveys as reported on the global database CRUST2.0. Details related to each of the measurement methodology have been described in the paper.

(v) Of particular interest is the constant SWV behaviour of the unweathered granitic/volcanic formations up to depth of $1.5 \mathrm{~km}$, which is distinguished from the SWV profile in sedimentary rock layers.

(vi) The upper crust amplification factor was derived from quarter-wavelength theory based on the developed SWV models.

(vii) The value of $\kappa$ for the upper crust of the four geological formations and the regional average SWV profile for Hong Kong have been determined from an empirical expression obtained in a previous study based on global information. The value for the regional average SWV profile has been further supported by inferences from parameters representing whole path attenuation and by assigning an appropriate set of 
weightings to the values of the four geological formations. The upper crust attenuation factor has been modelled in accordance with these values of $\kappa$.

(viii) The total filtering effects incorporating all amplification and attenuation factors have been obtained for the four geological formations commonly found in Hong Kong as well as the regional average. The regional average modification factor has been compared with those associated with the well-known Generic Rock and Generic Hard Rock crustal models of California and CENA, respectively.

(ix) Seismic waves reaching the rock surface in Hong Kong are potentially characterised by generally much lower-frequency behaviour than that in generic rock conditions such as in California. Seismic waves with frequency in the order of $0.3-1.0 \mathrm{~Hz}$ (period of 1-3 seconds) may be subject to the highest net amplification, which is in contrast to Generic Rock conditions and is a finding of engineering importance.

(x) Artificial accelerograms were generated in accordance with the seismological model developed for Hong Kong conditions. Response spectra were calculated accordingly for different earthquake scenarios. These response spectra were used to develop an attenuation relationship expressed in terms of the peak ground velocity (PGV). The highest response spectral velocity was divided by 1.8 to obtain the notional PGV.

(xi) Historical seismic intensity (MMI) data from seven historical earthquake events affecting Hong Kong has been transformed from MMI to PGV (mm/sec) based on the recommendation of Newmark and Rosenblueth (1971). The inferred PGV's and the modelled PGV's differed by a factor in the order of 1.0-1.8 (MMI increment of up to 0.8). The discrepancies can be explained by the fact that the modelled PGV's are based on rock conditions whereas the PGV's inferred from MMI data refer to average site conditions. Thus, the ground motion model developed from the methodology presented in this paper has been supported by comparison with macro-seismic data. 


\section{Acknowledgements}

This paper forms part of the outcome of major strategic research programmes undertaken by the Centre for Earthquake Engineering Research (CEER) at the University of Hong Kong in collaboration with the University of Melbourne to address seismic risk in regions of low and moderate seismicity worldwide. The work described in this paper was substantially supported by a grant from the Research Grants Council of the Hong Kong Special Administrative Region, China (Project No. HKU 7004/02E), whose support is gratefully acknowledged. The Australian programme has been undertaken at the University of Melbourne since 1993, and has received continuous funding from the Australian Commonwealth government. Invaluable contributions and support over the years by colleagues at both Universities (particularly A/Prof. Lung Chan, A/Prof. John Wilson and Prof. Graham Hutchinson) and by other research collaborators from Australia (including Professor Michael Asten and James Roberts of Monash University, Gary Gibson of the Seismology Research Centre, and Trevor Allen, Trevor Dhu and Cvetan Sinadinovski of Geoscience Australia), and from Singapore (A/Prof Balendra of NUS) are gratefully acknowledged. The authors are also very grateful to the encouragement and invaluable advice provided by Euan Smith, David Dowrick and Peter Davenport from New Zealand over the years.

\section{References}

Abercrombie, R.E., 1997. Near-surface attenuation and site effects from comparison of surface and deep borehole recordings. Bulletin of the Seismological Society of America 87(3), 731-744.

Aki, K., 1957. Space and time spectra of stationary stochastic waves, with special reference to microtremors. Bulletin of the Earthquake Research Institute 35, 415-456.

Aki, K., 1969. Analysis of the seismic coda of local earthquakes as scattered waves. Journal of Geophysical Research 74, 615-631.

Aki, K., Chouet, B., 1975. Origin of coda waves: source, attenuation, and scattering effects. Journal of Geophysical Research 80(23), 3322-3342.

Anderson, J.G., Hough, S.E., 1984. A model for the shape of the Fourier amplitude spectrum of acceleration at high frequencies. Bulletin of the Seismological Society of America 74(5), 1969-1993.

Arup, 1999. Kowloon Canton Railway Corporation (KCRC) West Rail Contract No.: TS-500 Full scale deep foundation load testing programme, (1) Milestone 12: Test Pile TSW1 Interpretative Report (Revision A), (2) Milestone 12: Test Pile TSW2 - Interpretative Report (Revision A), (3) Milestone 12: Test Pile TWW1 - Interpretative Report (Revision 
A), (4) Milestone 12: Test Pile TMC1 - Interpretative Report (Revision A) and (5) Milestone 12: Test Pile TMN1 - Interpretative Report (Revision A), August 1999.

Asten, M., Lam, N.T.K., Gibson, G., Wilson, J.L., 2002. Microtremor survey design optimized for application to site amplification and resonance modelling. Proceedings of Australia Earthquake Engineering Society Conference, Adelaide.

Atkinson, G.M., Mereu, R.F., 1992. The shape of ground motion attenuation curves in southeastern Canada. Bulletin of the Seismological Society of America 82(5), 2014-2031.

Atkinson, G.M., 1993. Earthquake source spectra in Eastern North America. Bulletin of the Seismological Society of America 83, 1778-1798.

Atkinson, G.M., Somerville, P.G., 1994. Calibration of time history simulation methods. Bulletin of the Seismological Society of America 84(2), 400-414.

Atkinson, G.M., Silva, W., 1997. An empirical study of earthquake source spectra for Californian earthquakes. Bulletin of the Seismological Society of America 87, 97-113.

Atkinson, G.M., Boore, D.M., 1998. Evaluation of models for earthquake source spectra in Eastern North America. Bulletin of the Seismological Society of America 88(4), 917-937.

Atkinson, G.M., Sonley E., 2000. Empirical relationships between modified Mercalli intensity and response spectra. Bulletin of the Seismological Society of America 90(2), 537-544.

Balendra, T., Lam, N.T.K., Wilson, J.L., Kong, K.H., 2002. Analysis of long-distance earthquake tremors and base shear demand for buildings in Singapore. Engineering Structures 24, 99-108.

Boore, D.M., Joyner, W.B., 1997. Site amplifications for generic rock sites. Bulletin of the Seismological Society of America 87(2), 327-341.

Chandler, A.M., Lam, N.T.K., 2002. Intensity attenuation relationship for the South China region and comparison with the component attenuation model. Journal of Asian Earth Sciences 20, 775-790.

Chandler, A., Lam, N., 2004. An attenuation model for distant earthquakes. Earthquake Engineering and Structural Dynamics 33(2), 183-210.

Chandler, A.M., Lam N.T.K., Tsang H.H., 2005a. Shear wave velocity modelling in crustal rock for seismic hazard analysis. Soil Dynamics and Earthquake Engineering 25, 167 185.

Chandler, A.M., Lam, N.T.K., Tsang H.H., 2005b. Near-surface attenuation modelling based on rock shear wave velocity profile. Soil Dynamics and Earthquake Engineering (under review).

Chandler, A.M., Su, R.K.L., 2000. Dynamic soil properties of Hong Kong reclamation sites for seismic applications. Transactions of the Hong Kong Institution of Engineers 7(1), 1327.

Chan, L.S., Bell, J.D., 2000. The use of continuous surface wave method to determine in-situ stiffness profiles within a natural terrain setting in Hong Kong. Society Application Geophysics to Engineering and Environmental Practice Proceeding, 195-204.

Chen, P.S., Nuttli, O.W., 1984. Estimates of magnitude and short-period wave attenuation of Chinese earthquake from modified Mercalli intensity data. Bulletin of the Seismological Society of America 74(3), 957-968.

Electronic and Geophysical Services (EGS) Asia Limited, 1998. (1) KCRC West Rail Contract No.: FCC-017 Full scale deep foundation load testing Yen Chow Street and Tsuen Wan West Stations crosshole seismic measurement final report, September 1998 
and (2) KCRC West Rail Contract No.: FCC-016 Full scale deep foundation load testing Yuen Long, Long Ping and Tin Shui Wai Stations crosshole seismic measurement final report, October 1998.

Electronic and Geophysical Services (EGS) Asia Limited, 2001. Ground investigation term contract for geotechnical studies 1999-2001 HKHA Contract No. 144 of 1998 Works Order No. 135 Borehole geophysical survey to Fanling area 36, Phase 3 and 4, final report, April 2001.

Gaull, B.A., Michael-Leiba, M.O., Rynn, J.M.W., 1990. Probabilistic earthquake risk maps of Australia. Australian Journal of Earth Sciences 37, 169-187

Global Crustal Model CRUST2.0., 2001. Institute of Geophysics and Planetary Physics, Univ. of California, San Diego. http://mahi.ucsd.edu/Gabi/rem.dir/crust/crust2.html

Halcrow, 1999. Additional site reconnaissance and ground investigation factual report Volume 3: Civil Engineering Department Consultancy Agreement No. CE42/98 Natural terrain hazard and risk area studies Mount Johnston North and Tung Chung East, August 1999, Halcrow Asia Partnership Limited.

Jin, A., Aki, K., 1988. Spatial and temporal correlation between coda $Q$ and seismicity in China. Bulletin of the Seismological Society of America 78(2), 741-769.

Joyner, W.B., Warrick, R.E., Fumal, T.E., 1981. The effect of Quaternary alluvium on strong ground motion in the Coyote Lake, California, earthquake of 1979. Bulletin of the Seismological Society of America 71, 1333-1349.

Kramer, S.L., 1996. Geotechnical Earthquake Engineering, Prentice Hall, Upper Saddle River, New Jersey.

Lam, N.T.K., Chandler, A.M., Wilson, J.L., Hutchinson, G.L., 1999. Seismic hazard determination for the coastal region of South China (I): generic crustal modelling. Journal of Seismology and Earthquake Engineering 2(1), 1-18.

Lam, N., Wilson, J., Hutchinson, G., 2000a. Generation of synthetic earthquake accelerograms using seismological modelling: a review. Journal of Earthquake Engineering 4(3), 321-354.

Lam, N., Wilson, J., Chandler, A., Hutchinson, G., 2000b. Response spectral relationships for rock sites derived from component attenuation model. Earthquake Engineering and Structural Dynamics 29, 1457-1489.

Lam, N.T.K., Wilson, J.L., Chandler, A.M., Hutchinson, G.L., 2002. Response spectrum predictions for potential near-field and far-field earthquakes affecting Hong Kong: rock sites. Soil Dynamics and Earthquake Engineering 22, 47-72.

Lam, N.T.K., Sinadinovski, C., Koo, R.C.H., Wilson, J.L., 2003. Peak ground velocity modelling for Australian earthquakes. International Journal of Seismology and Earthquake Engineering 5(2), 11-22.

Lam, N.T.K., Asten M.W., Roberts, J., Venkatesan, S., Wilson J.L., Chandler, A.M., 2004. A generic tool for modelling earthquake hazard. Proceedings of the 18th Australasian Conference on the Mechanics of Structures \& Materials, Perth, 1-3 December 2004: Vol.1, pp.473-478.

Lam, N.T.K., Venkatesan, S., Wilson, J.L., Asten, M.W., Roberts, J., Chandler, A.M. Tsang, H.H., 2005. Generic approach for modelling seismic hazard. Invited paper by International Journal for Advances in Structural Engineering (accepted and in-press).

Mak, S., Chan, L.S., Chandler, A.M., Koo R.C.H., 2004. Coda Q estimates in the Hong Kong region. Journal of Asian Earth Sciences 24, 127-136. 
Mak, S., 2005. Seismic analysis for the South China region. MPhil Thesis, Department of Earth Sciences, The University of Hong Kong.

Newmark, N.M., Rosenblueth, E., 1971. Fundamentals of earthquake engineering. PrenticeHall, New Jersey.

Roberts, J., Asten, M.W., Tsang, H.H., Venkatesan, S., Lam, N.T.K., 2004. Shear wave velocity profiling in Melbourne Silurian mudstone using the SPAC method, Australian Earthquake Engineering in the New Millennium, Proceedings of a Conference of the Australian Earthquake Engineering Society (AEES), Mount Gambier, South Australia, Paper 15.

Sadigh, K., Chang, C.Y., Egan, J.A., Makdisi, F., Youngs, R.R., 1997. Attenuation relationships for shallow crustal earthquakes based on Californian strong motion data, Seismological Research Letters 68(1), 180-189.

Schnabel, P.B., Lysmer, J., Seed, H.B., 1972. A computer program for earthquake response analysis of horizontally layered sites. Earthquake Engineering Research Centre EERC report 72-12. Berkeley (CA): University of California at Berkeley.

Shum, D.Y.N., 2003. The determination of small strain soil stiffness for the seismic design of Stonecutters Bridge. Ove Arup and Partners Hong Kong Limited. (Paper submitted to the Fugro Prize organised by Hong Kong Institution of Engineers Geotechnical Division).

Tam, K.W., 2002. Anisotropy in seismic wave velocity of joined igneous rock. MPhil Thesis, Department of Earth Sciences, The University of Hong Kong.

Tsang, H.H., Chandler, A.M., 2005. Site-specific probabilistic seismic hazard assessment: direct amplitude-based approach, Bulletin of the Seismological Society of America (under review).

Tsang, H.H., Roberts, J., Asten, M, Chandler, A.M., Lam, N.T.K., Chan, L.S., 2005. Modelling shear wave velocity profiles in rock using spatial auto-correlation technique: the Hong Kong case study. Proceedings of the Annual Technical Conference of the Australian Earthquake Engineering Society, Albury, Victoria, 2005 (paper to be presented in November 2005).

Wilson, J.L., Lam, N.T.K., 2003. A recommended earthquake response spectrum model for Australia. Australian Journal of Structural Engineering, Institute of Engineers 5(1), 17-27.

Wong, Y.L., Lam, E.S.S., Zhao, J.X.Z., Chau, K.T., 1998. Assessing seismic response of soft soil sites in Hong Kong using microtremor records. HKIE Transactions 5(3), 70-78.

Wong, Y.L., Zheng, S., Liu, J., Kang, Y., Tam, C.M., Leung, Y.K., Zhao, X., 2002. Attenuation function of ground motions and source parameters for Guangdong region of Southern China, International Conference on Advances and New Challenges in Earthquake Engineering Research, Hong Kong, 19-20. 
Table $1 \quad$ Upper-crust attenuation parameter $\kappa$ for the four prevalent geological formations and regional average for Hong Kong

\begin{tabular}{ccc}
\hline Rock Types & $V_{u c}(\mathrm{~km} / \mathrm{s})$ & $\kappa[$ Eq. (14)] \\
\hline Granitic & 2.56 & 0.032 \\
Volcanic & 2.73 & 0.024 \\
Heavily-jointed Volcanic & 2.49 & 0.036 \\
Meta-sedimentary & 2.40 & 0.040 \\
Regional Average & 2.62 & 0.030 \\
\hline
\end{tabular}


Table 2 Comparison of historical MMI data (Hong Kong) with the attenuation relationships presented in this study

\begin{tabular}{ccccccccccc}
\hline Year & $\mathrm{N}$ & $\mathrm{E}$ & $\mathrm{M}$ & $\mathrm{R}$ & $Q_{0}$ Hong Kong & $\begin{array}{c}\text { MMI in } \\
\text { Inferred }\end{array}$ & $\begin{array}{c}\text { Modelled } \\
P G V \\
(\mathrm{~mm} / \mathrm{s})\end{array}$ & $\begin{array}{c}\text { Implied Site } \\
\text { Factor (ratio } \\
\text { of } P G V)\end{array}$ & $\begin{array}{c}\text { Implied } \\
\text { MMI }\end{array}$ \\
\hline 1067 & 23.6 & 116.5 & 6.8 & 289 & 369 & 5 & 37 & 15 & 2.5 & 1.3 \\
1604 & 24.7 & 119 & $7.5-8$ & 585 & 517 & 5 & 50 & 18 & 2.8 & 1.5 \\
1605 & 20 & 110.5 & $7.5-8$ & 479 & 464 & 5 & 50 & 22 & 2.3 & 1.2 \\
1874 & 22.1 & 114.4 & 5.8 & 32 & 256 & 6 & 66 & 45 & 1.5 & 0.6 \\
1905 & 22.1 & 113.4 & 5.5 & 89 & 256 & 5 & 26 & 14 & 1.9 & 0.9 \\
1918 & 23.5 & 117 & 7.3 & 331 & 390 & 5 & 47 & 22 & 2.1 & 1.1 \\
1962 & 23.7 & 114.7 & 6.1 & 172 & 256 & 5 & 29 & 13 & 2.2 & 1.1 \\
\hline
\end{tabular}




\section{LIST OF FIGURES}

Fig. 1. Magnitude dependent generic intra-plate source Fourier spectrum for acceleration amplitude.

Fig. 2. Anelastic whole path attenuation factor for the South China region surrounding Hong Kong.

Fig. 3. Shear wave velocity (SWV) measurements obtained from instrumented boreholes for weathered rock materials in Hong Kong: (a) Granitic Formations; (b) Volcanic Formations; (c) Heavily-Jointed Volcanic Formations; (d) Meta-Sedimentary Formations (Schist).

Fig. 4. Crustal shear wave velocity (SWV) obtained from SPAC measurements after Tsang et al. (2005).

Fig. 5. Crustal shear wave velocity (SWV) obtained from monitoring of quarry blasts: (a) Granitic Formations; (b) Volcanic Formations.

Fig. 6. Crustal shear wave velocity (SWV) profile models for Hong Kong.

Fig. 7. Comparison of the regional average shear wave velocity (SWV) profile for Hong Kong with regional profiles for generic rock (GR) and generic hard rock (GHR) proposed by Boore and Joyner (1997) [BJ97].

Fig. 8. Variation of the upper-crust amplification factors $V(f)$ with frequency for the four geological formations and the regional average for Hong Kong.

Fig. 9. Variation of the upper-crust modification factors with frequency for the four geological formations and the regional average for Hong Kong.

Fig. 10. Crustal amplification, attenuation and combined modification factors for Hong Kong [regional averages].

Fig. 11. Comparison of upper-crustal modification factor for Hong Kong with those of the generic rock (GR) and the generic hard rock (GHR) models of Boore and Joyner (1997) [BJ97].

Fig. 12. Response spectra simulated at a reference source-site distance $R=30 \mathrm{~km}$, (a) $M=6$ for the four geological formations and the regional average for Hong Kong; (b) different earthquake scenarios based on regional average conditions. 
Fig. 13. Comparison of Peak Ground Velocity (PGV) with historical MMI data for the Hong Kong region.

Fig. A1. Simplified geological map of Hong Kong and locations of SPAC surveys.

Fig. A2. Examples of SPAC array configurations employed in Hong Kong surveys:

(a) Hexagonal array with radius $=50 \mathrm{~m}$; (b) Triangular array with outer radius $=95 \mathrm{~m}$. 


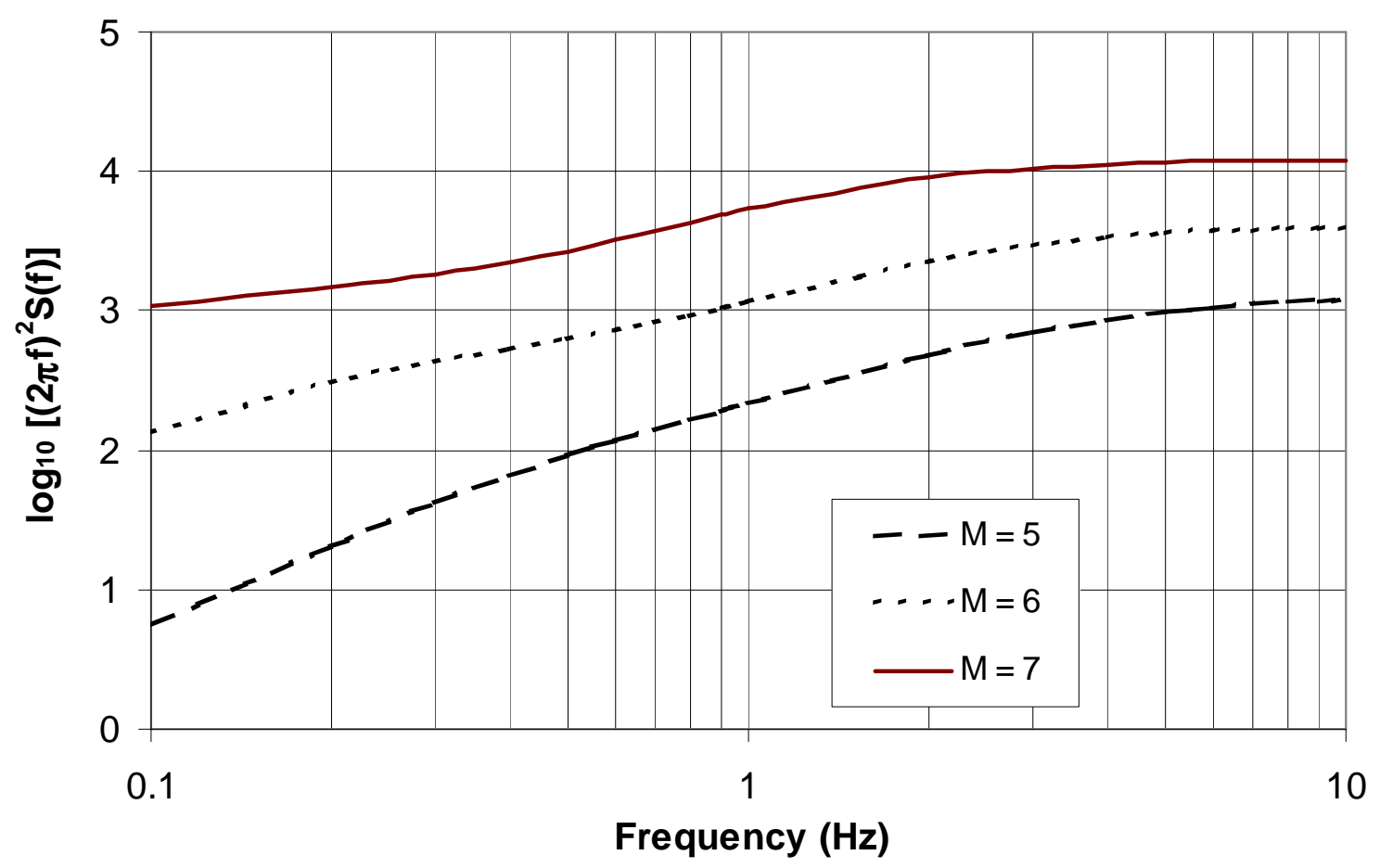

Fig. 1. Magnitude dependent generic intra-plate source Fourier spectrum for acceleration amplitude.

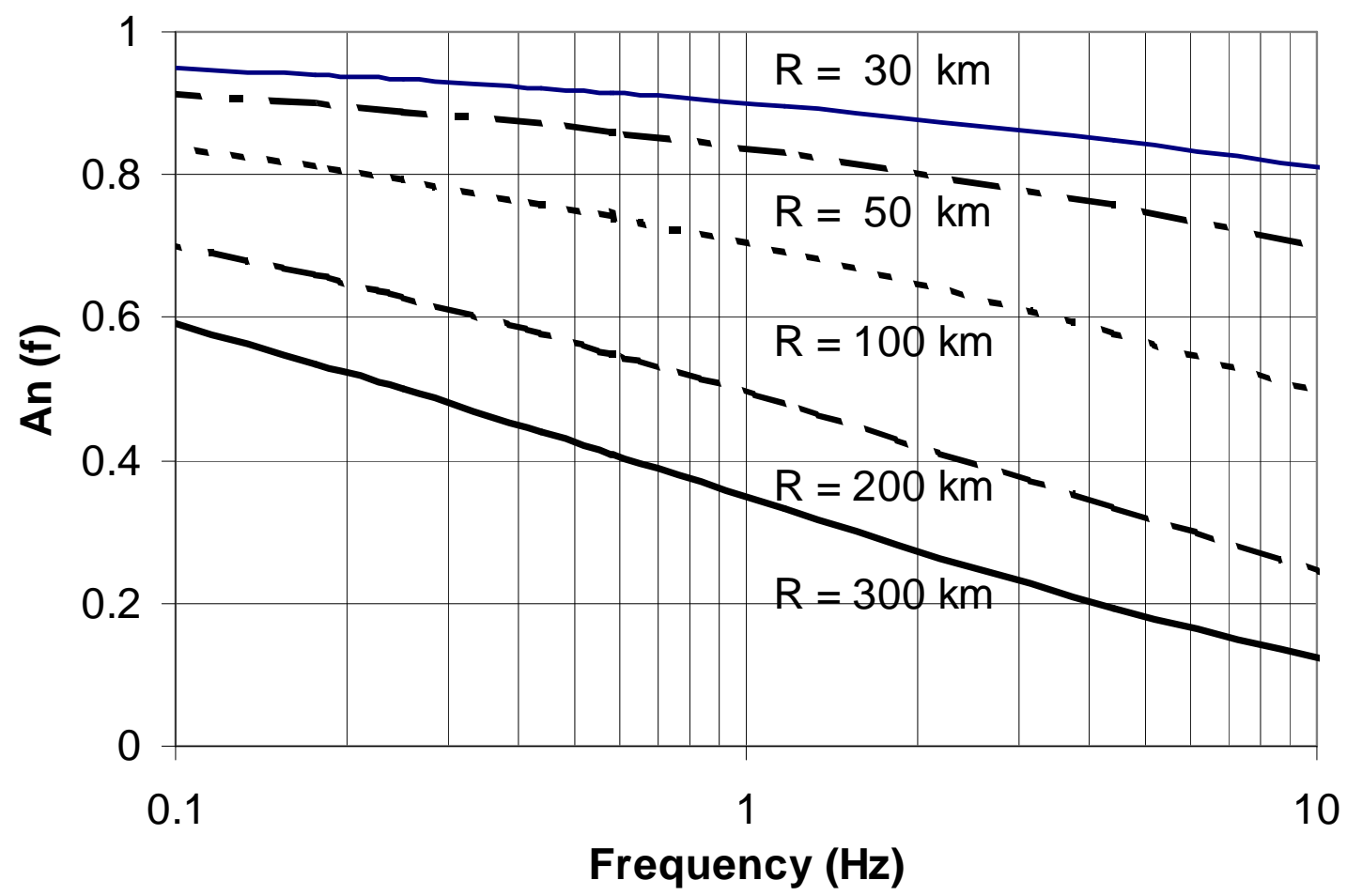

Fig. 2. Anelastic whole path attenuation factor for the South China region surrounding Hong Kong. 


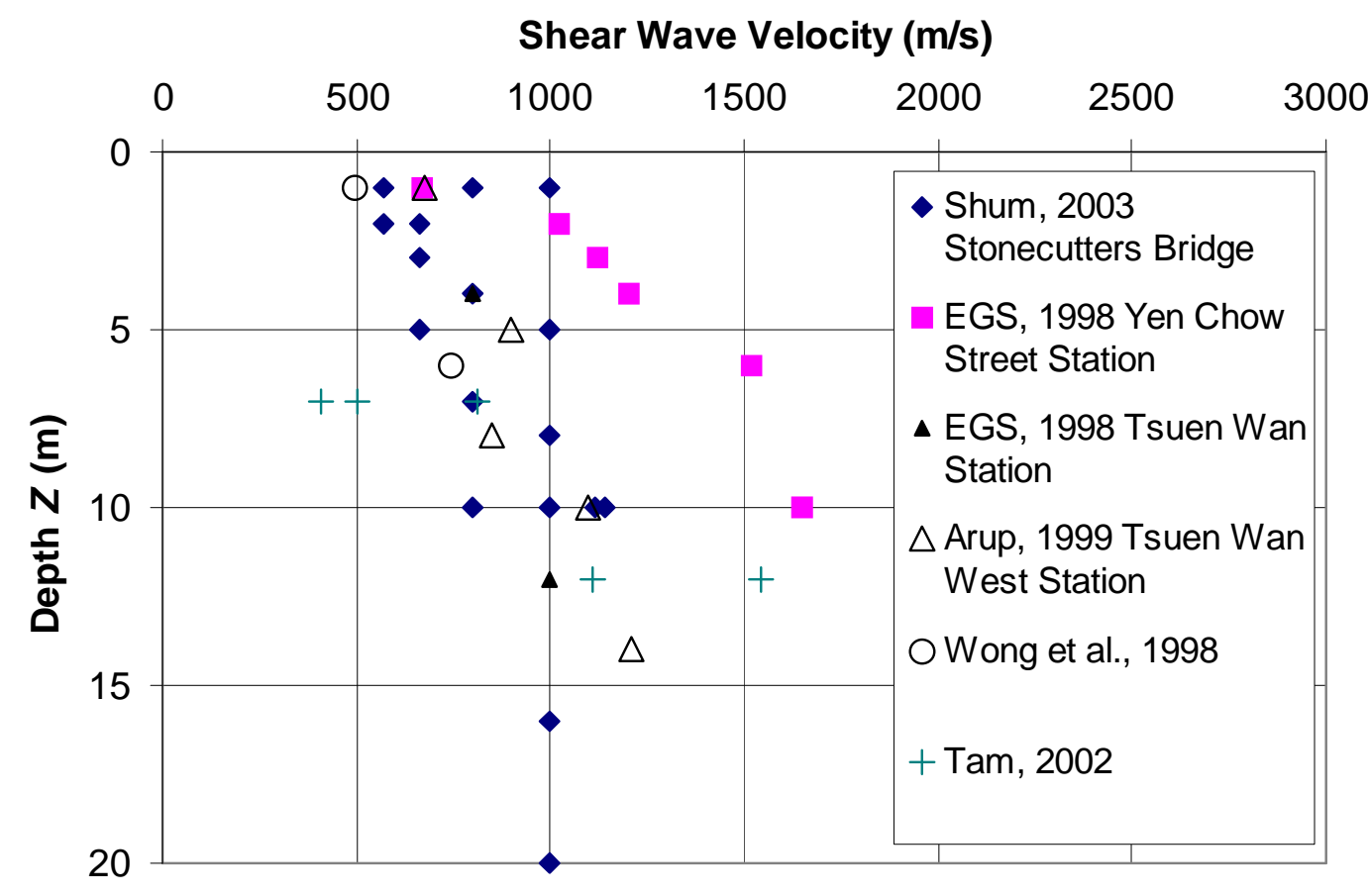

(a) Granitic Formations

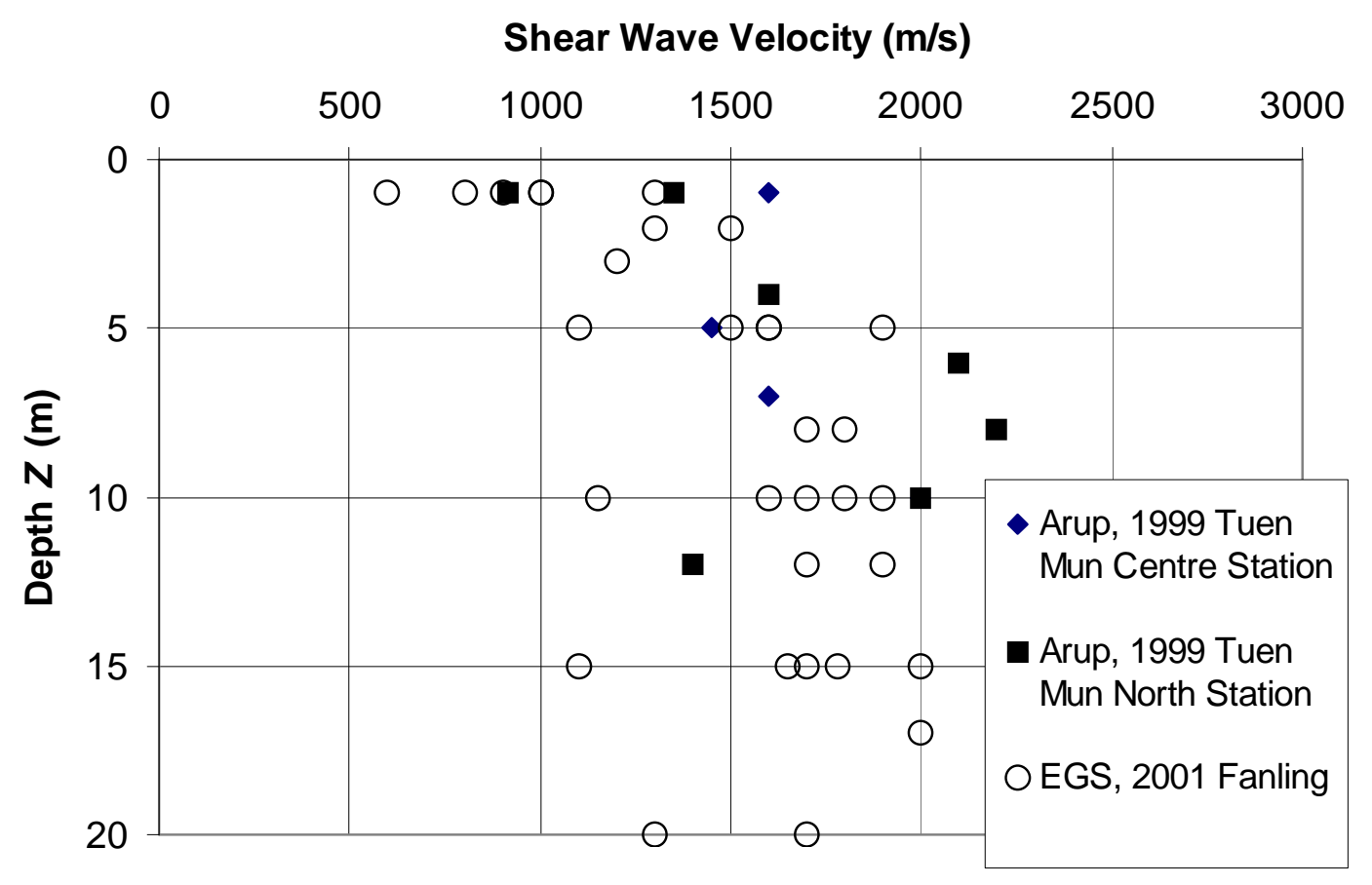

(b) Volcanic Formations

Fig. 3. Shear wave velocity (SWV) measurements obtained from instrumented boreholes for weathered rock materials in Hong Kong: (a) Granitic Formations; (b) Volcanic Formations. 


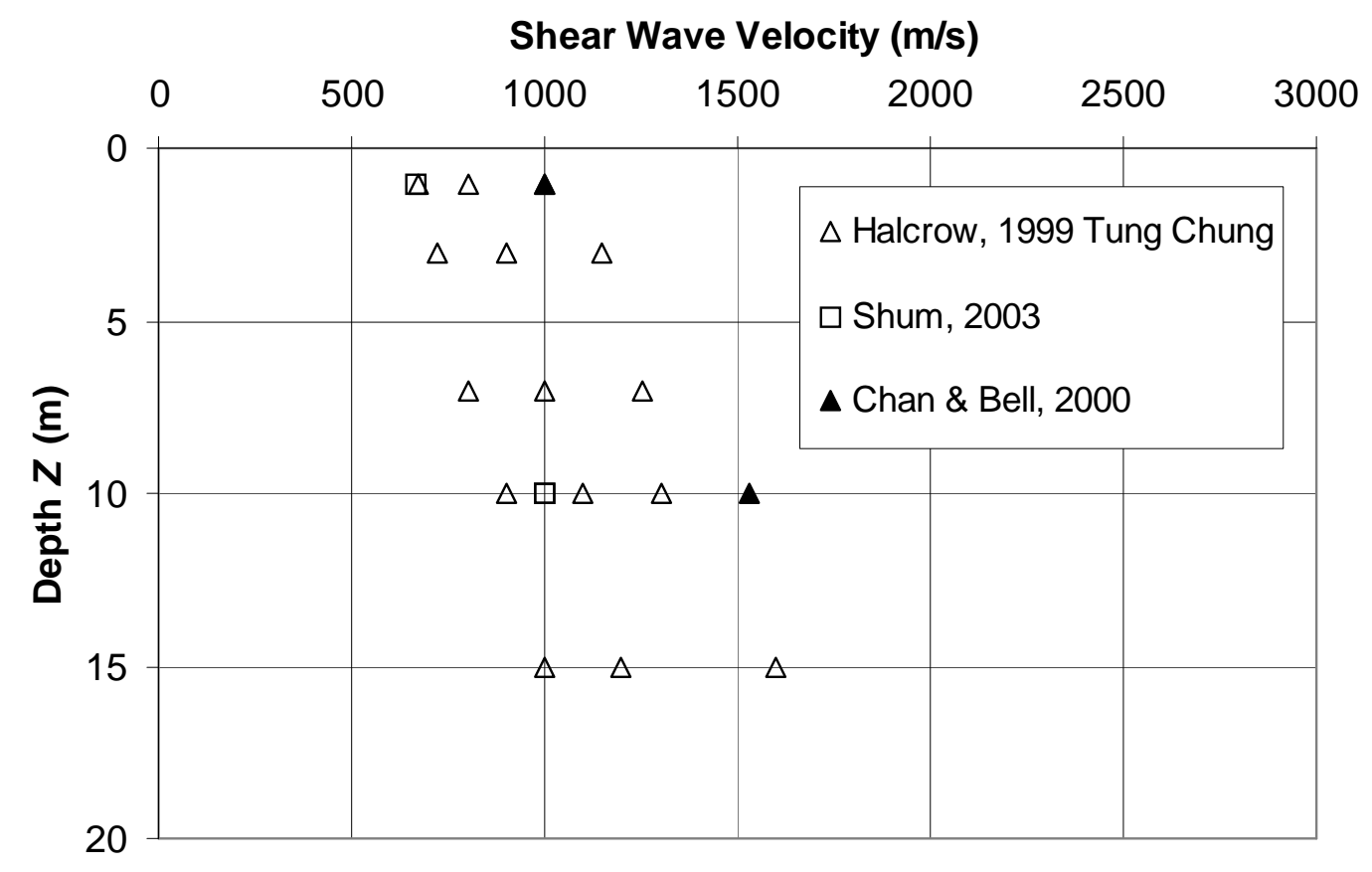

(c) Heavily-Jointed Volcanic Formations

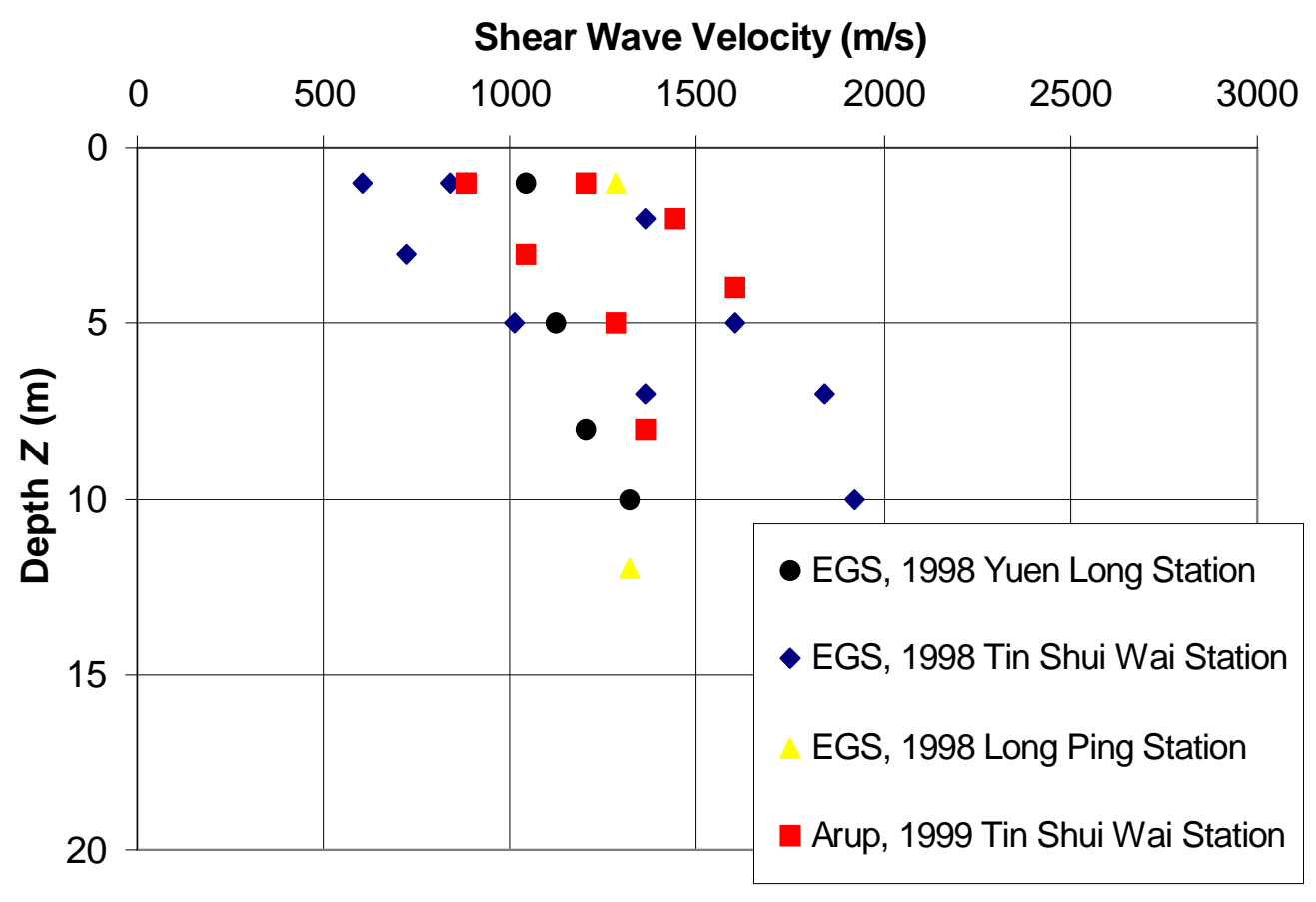

(d) Meta-Sedimentary Formations (Schist)

Fig. 3. Shear wave velocity (SWV) measurements obtained from instrumented boreholes for weathered rock materials in Hong Kong: (c) Heavily-Jointed Volcanic Formations; (d) Meta-Sedimentary Formations (Schist). 


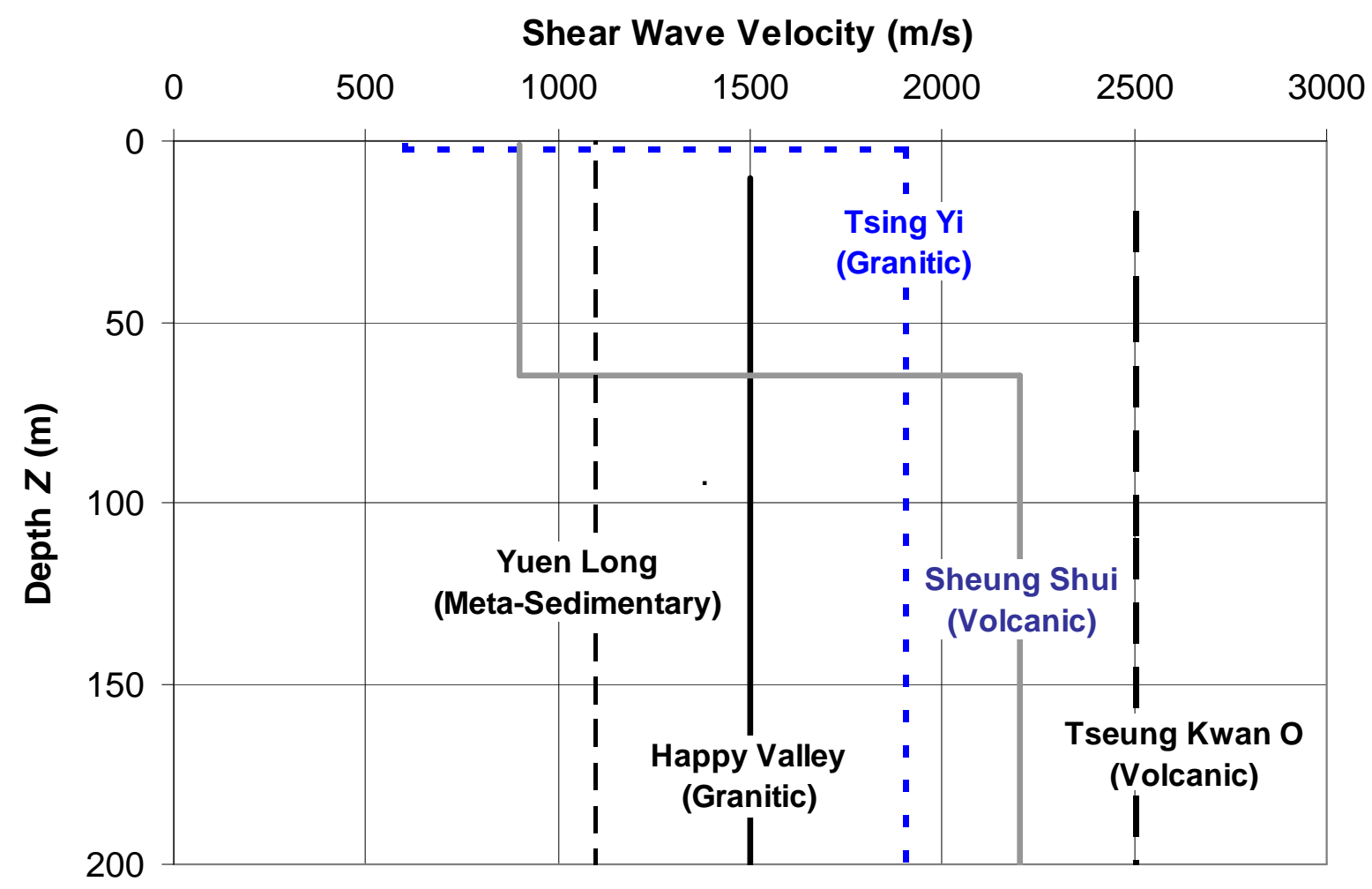

Fig. 4. Crustal shear wave velocity (SWV) obtained from SPAC measurements after Tsang et al. (2005). 


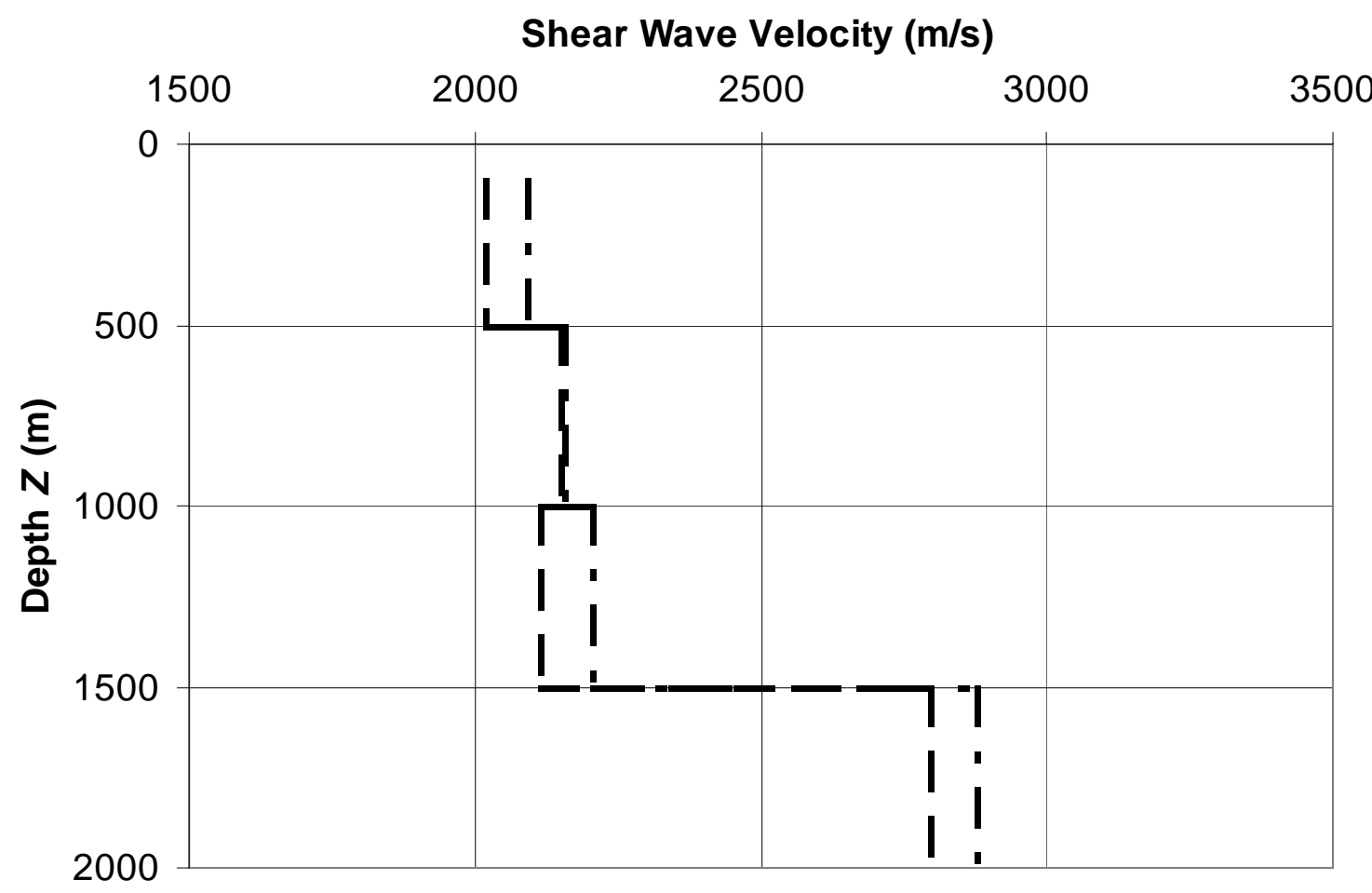

(a) Granitic Formations

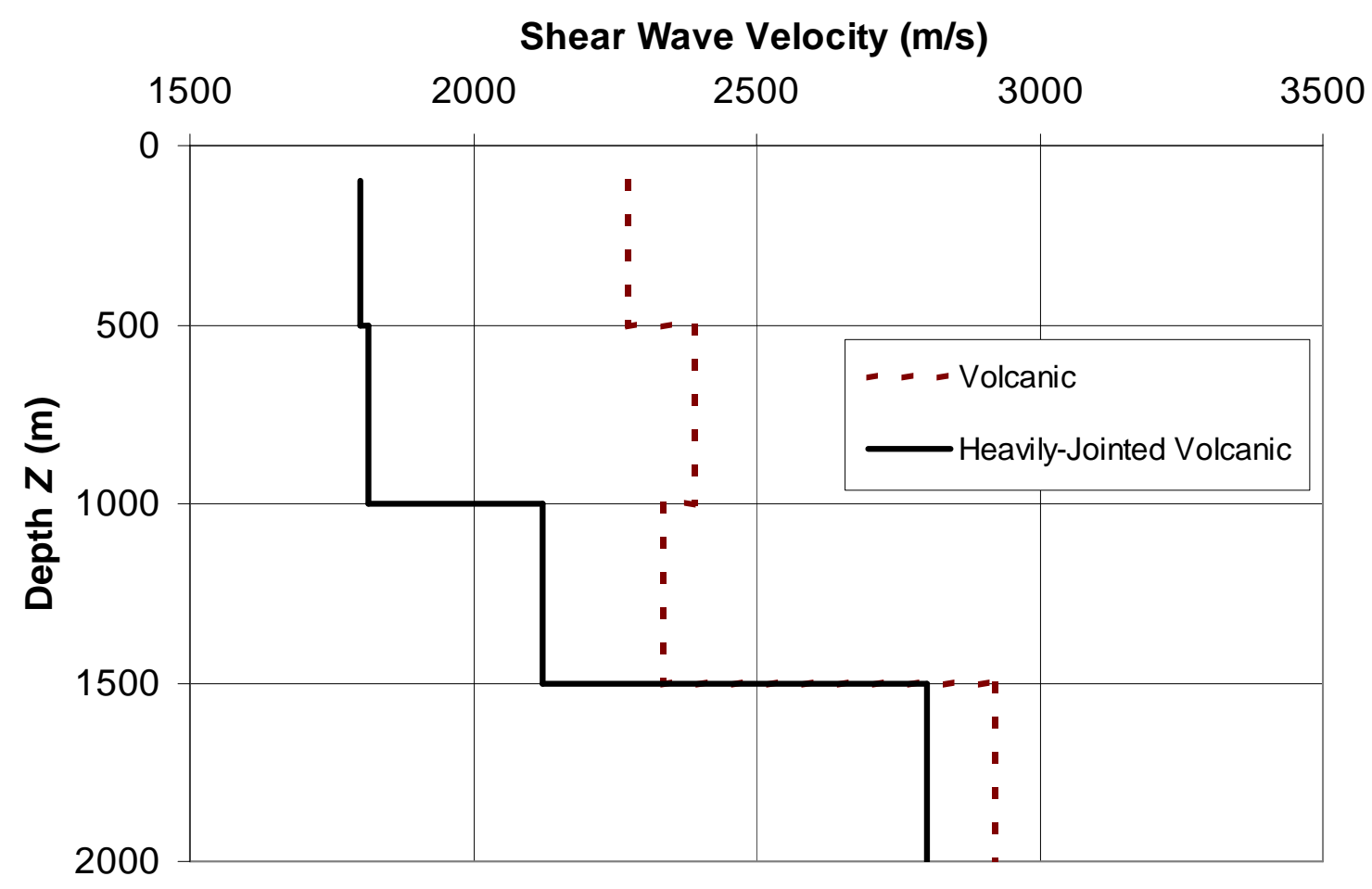

(b) Volcanic Formations

Fig. 5. Crustal shear wave velocity (SWV) obtained from monitoring of quarry blasts: (a) Granitic Formations; (b) Volcanic Formations. 


\section{Shear Wave Velocity $(\mathrm{m} / \mathrm{s})$}

100 1000

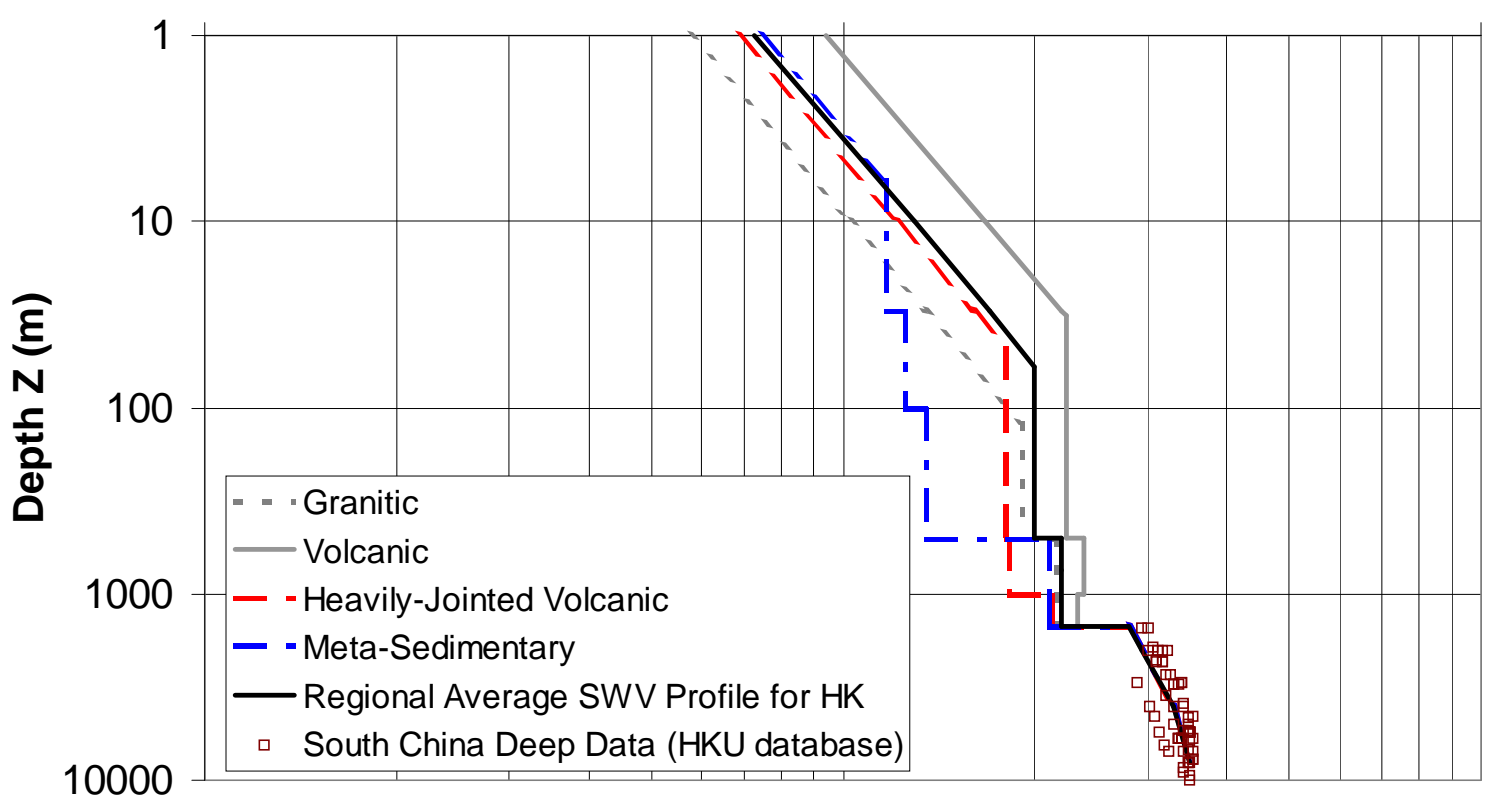

Fig. 6. Crustal shear wave velocity (SWV) profile models for Hong Kong.

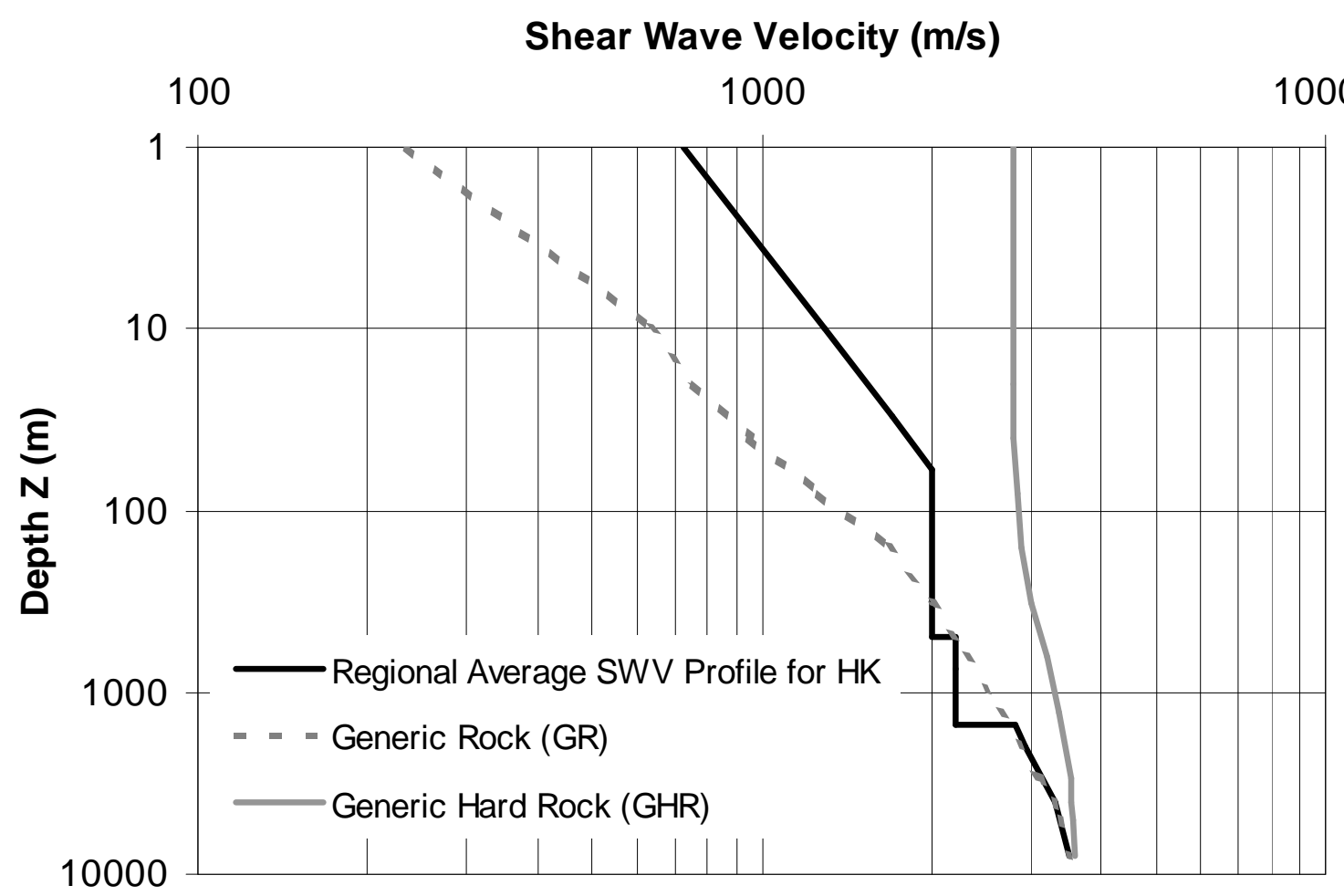

Fig. 7. Comparison of the regional average shear wave velocity (SWV) profile for Hong Kong with regional profiles for generic rock (GR) and generic hard rock (GHR) proposed by Boore and Joyner (1997) [BJ97]. 


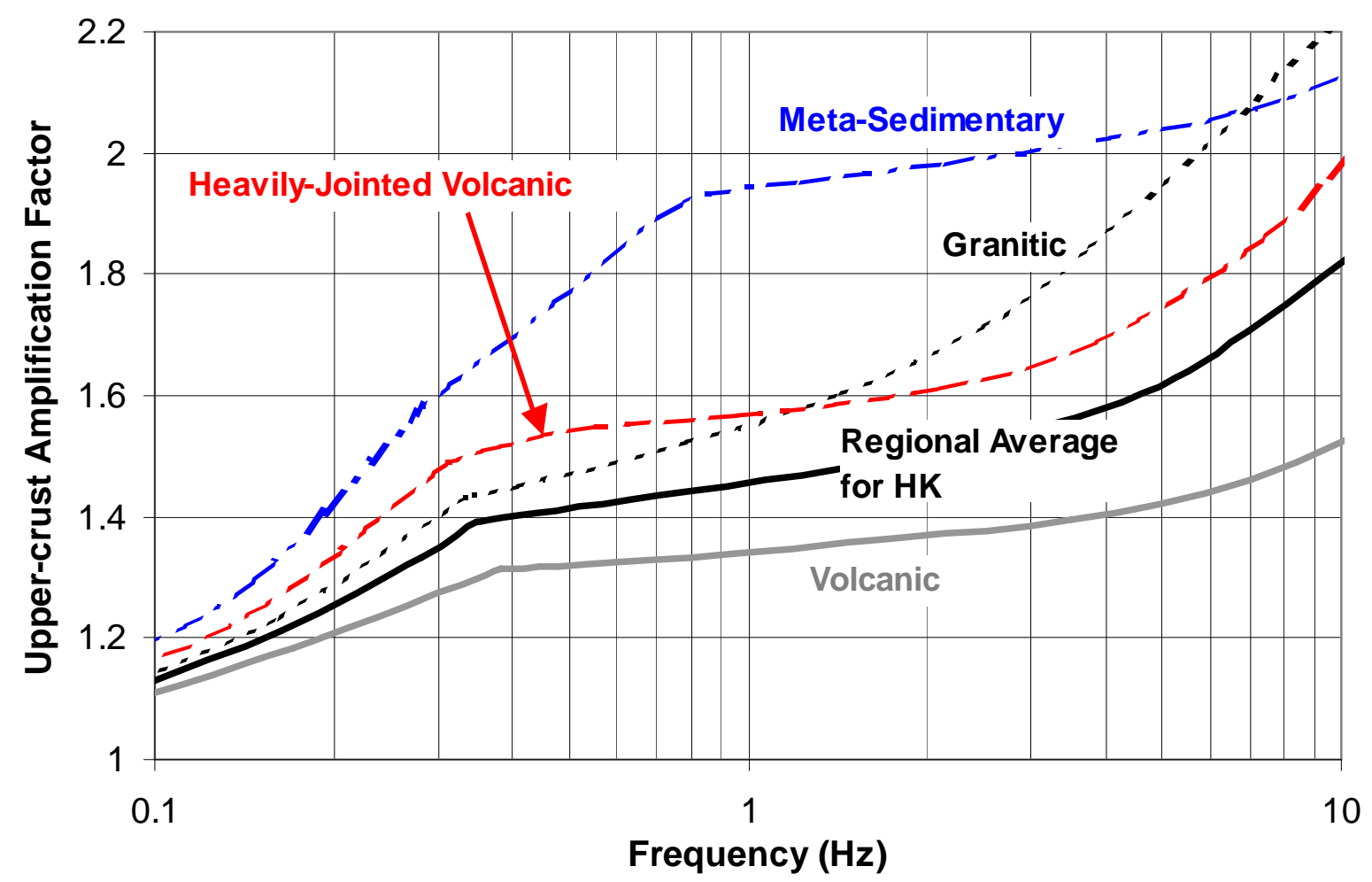

Fig. 8. Variation of the upper-crust amplification factors $V(f)$ with frequency for the four geological formations and the regional average for Hong Kong. 


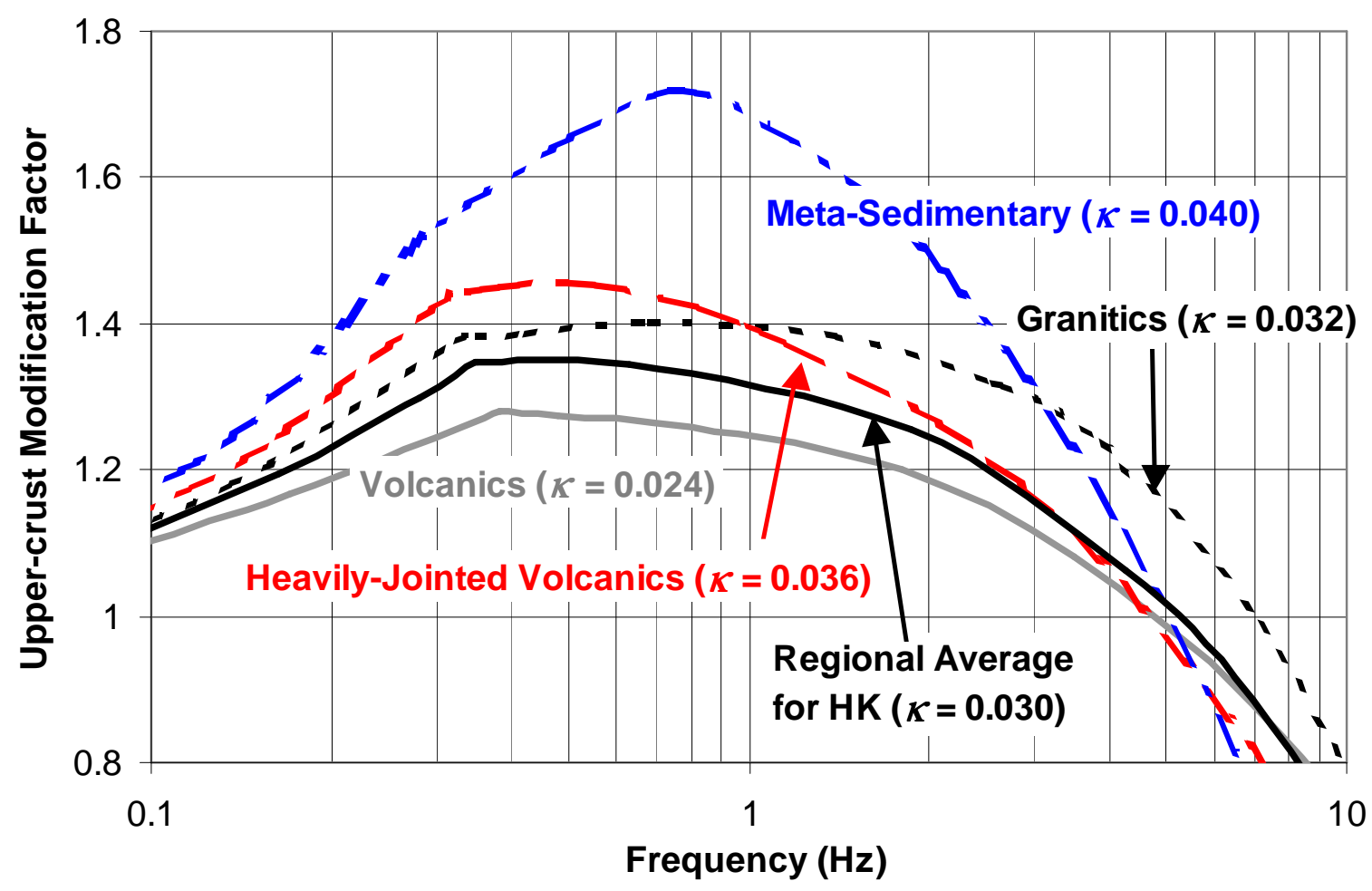

Fig. 9. Variation of the upper-crust modification factors with frequency for the four geological formations and the regional average for Hong Kong.

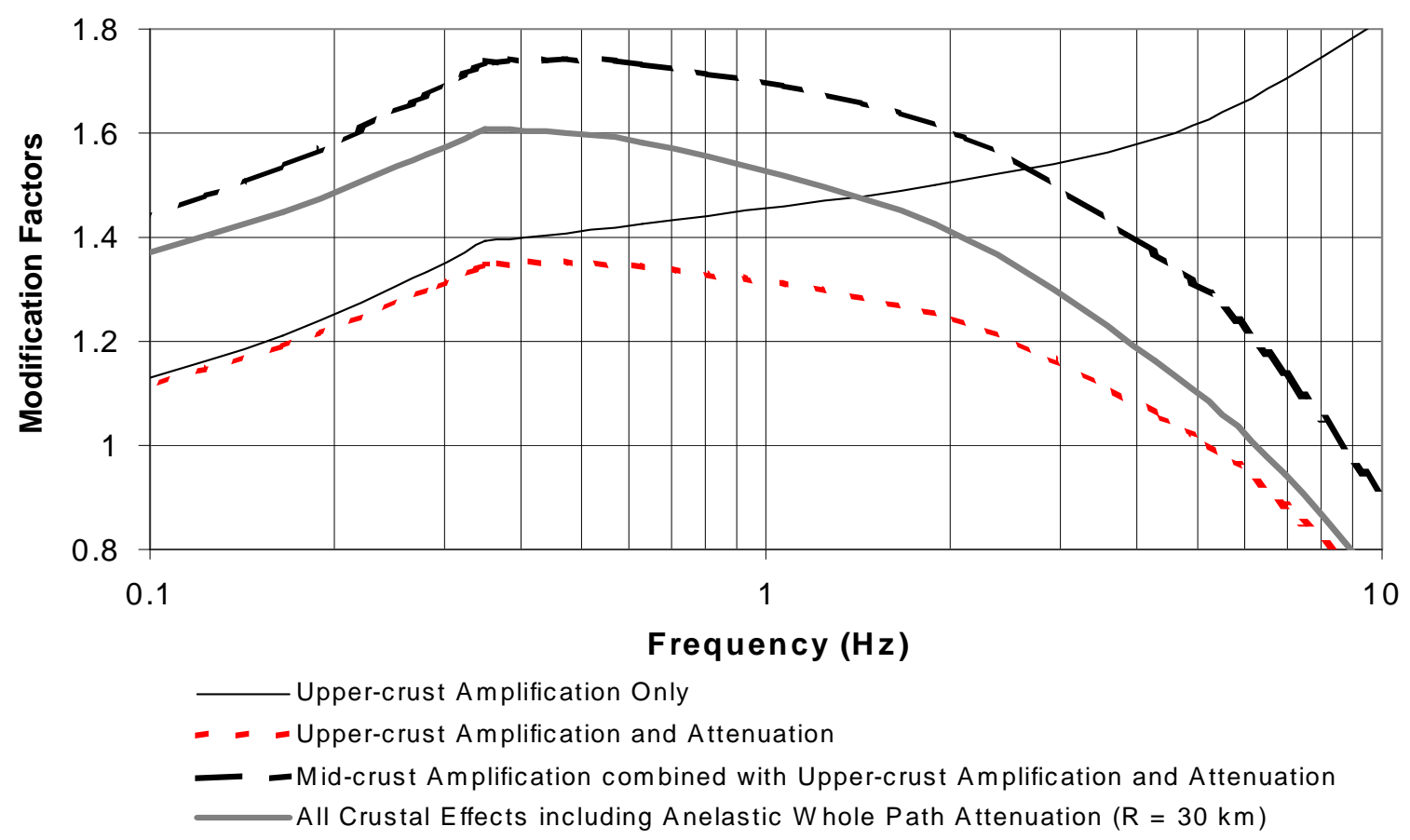

Fig. 10. Crustal amplification, attenuation and combined modification factors for Hong Kong [regional averages]. 


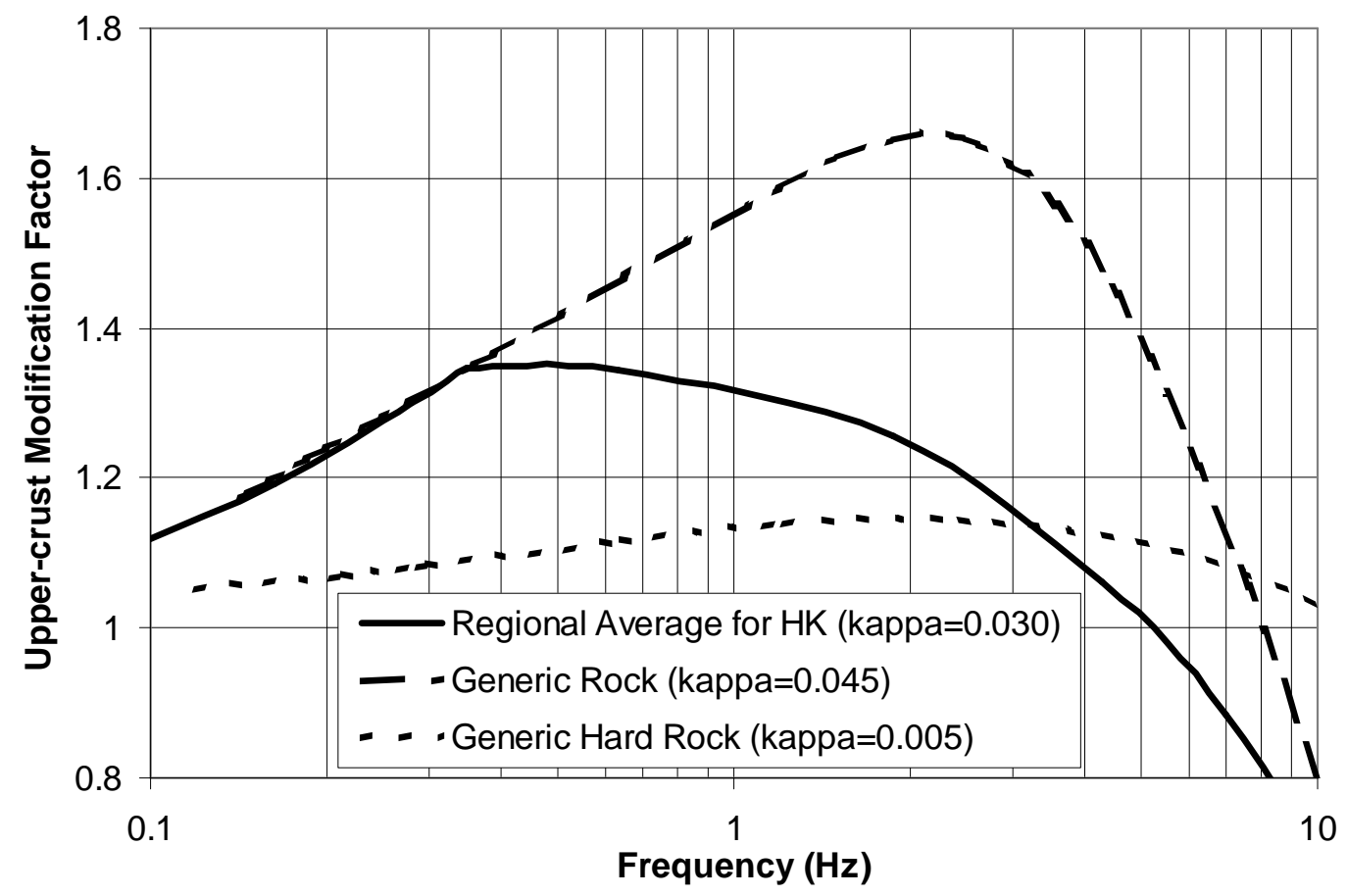

Fig. 11. Comparison of upper-crustal modification factor for Hong Kong with those of the generic rock (GR) and the generic hard rock (GHR) models of Boore and Joyner (1997) [BJ97]. 


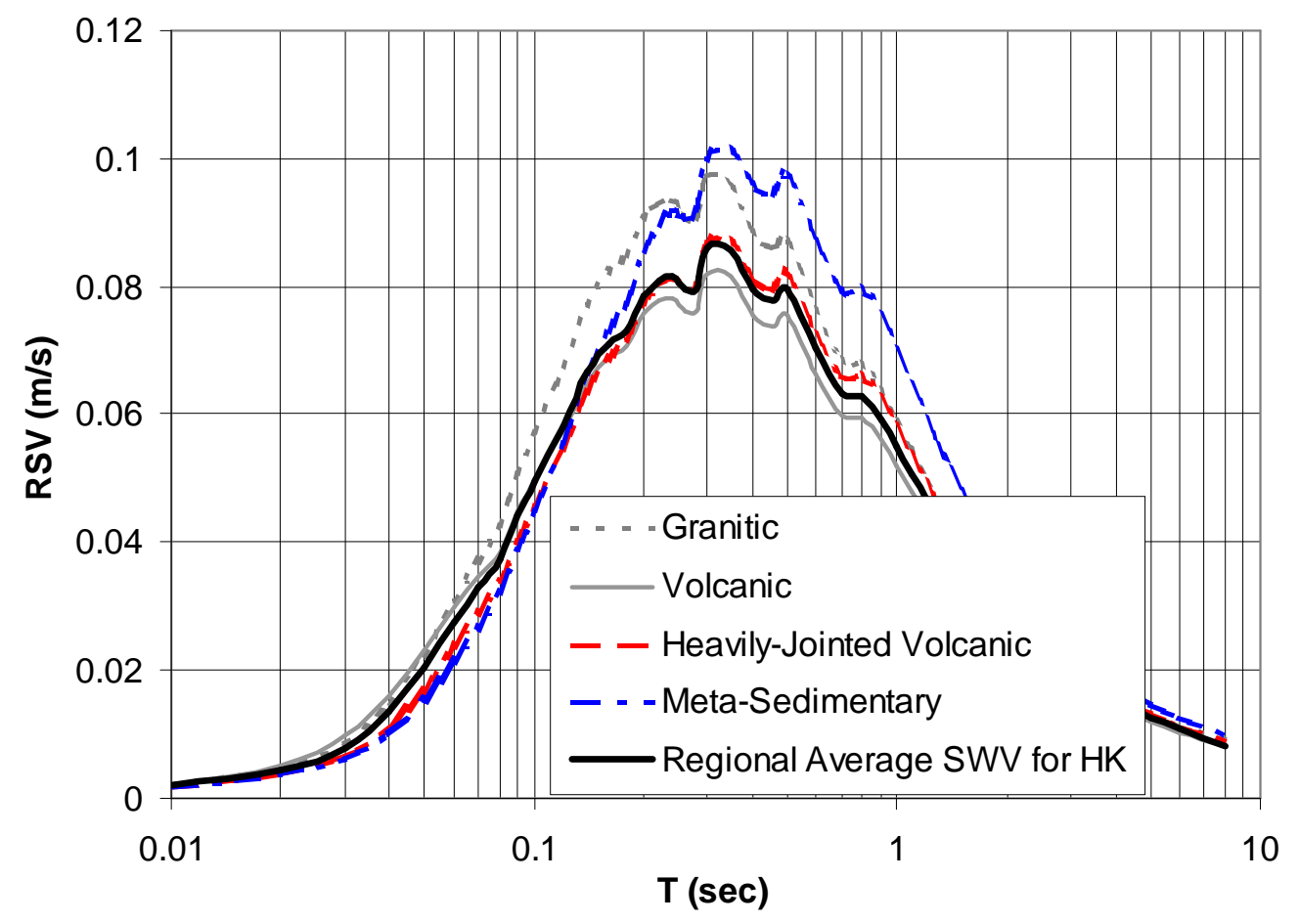

(a) $M=6$ earthquakes

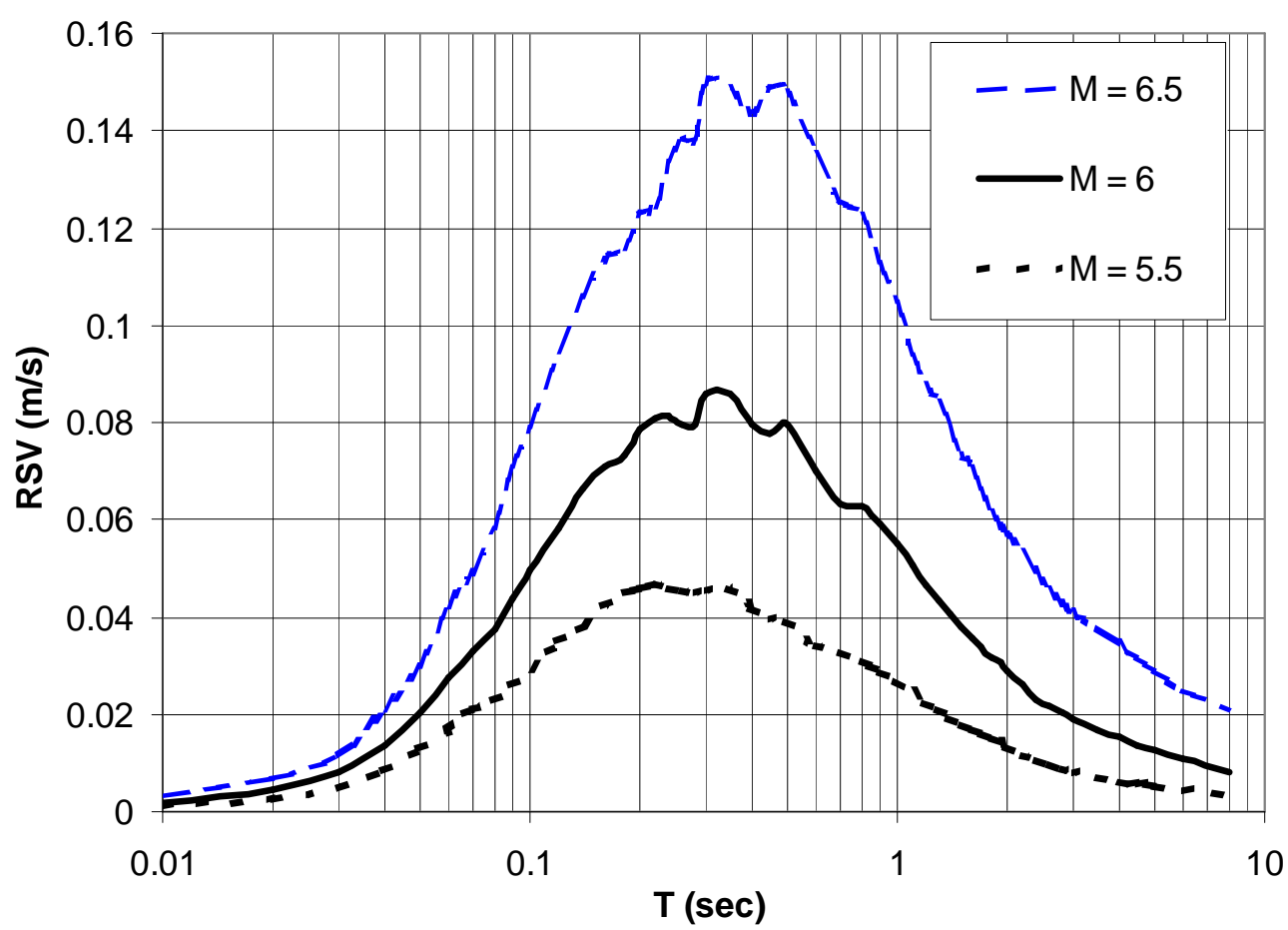

(b) Different earthquake scenarios based on regional average conditions

Fig. 12. Response spectra simulated at a reference source-site distance $R=30 \mathrm{~km}$ (a) $M=6$ for the four geological formations and the regional average for Hong Kong; (b) different earthquake scenarios based on regional average conditions. 


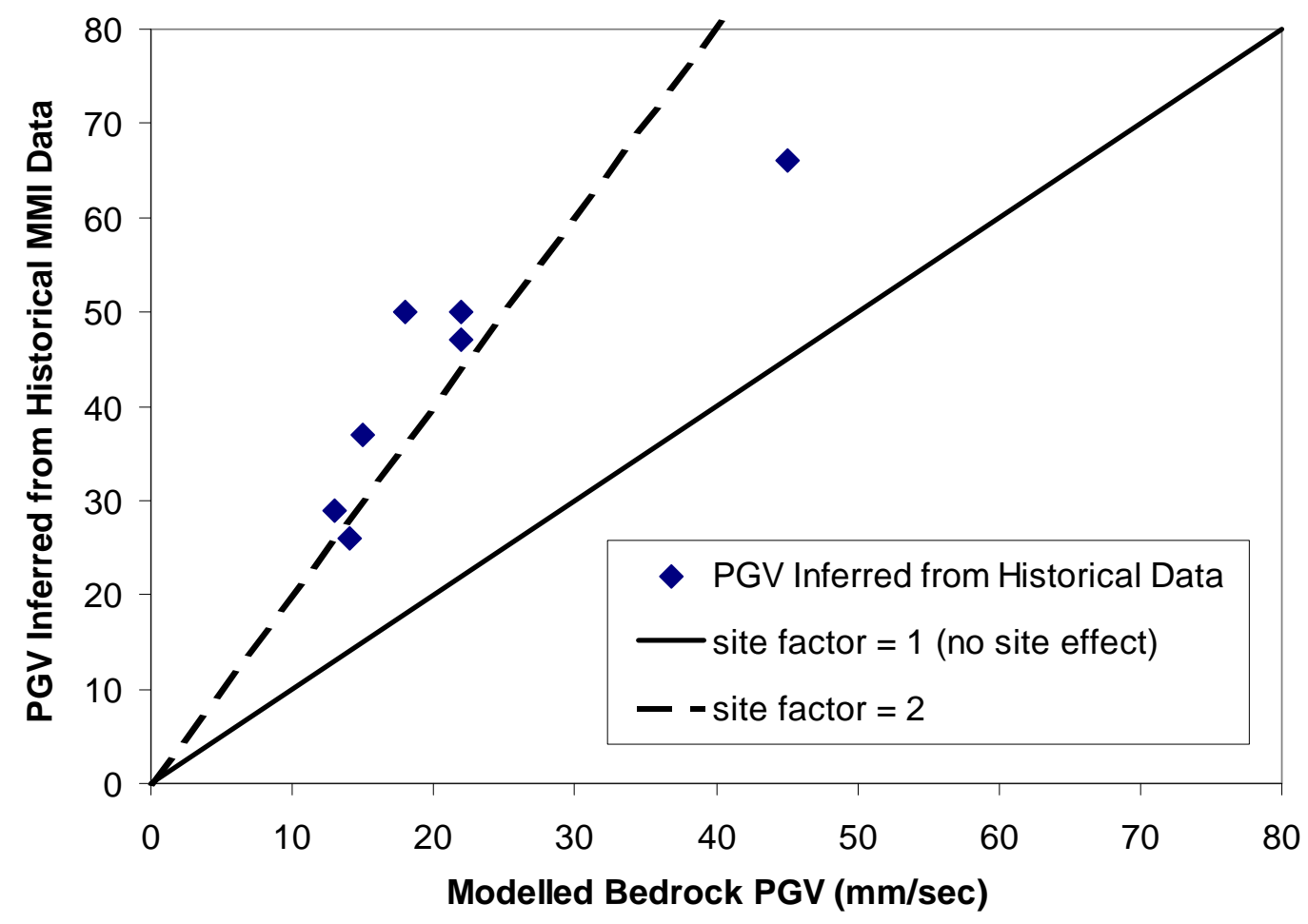

Fig. 13. Comparison of Peak Ground Velocity (PGV) with historical MMI data for the Hong Kong region. 


\section{Appendix A}

Table A1 Details of SPAC surveys conducted in Hong Kong

\begin{tabular}{|c|c|c|c|c|}
\hline $\begin{array}{c}\text { Site No. } \\
\text { (refer Fig. A1) }\end{array}$ & Site Location & Site Name & $\begin{array}{l}\text { Array Configuration } \\
\quad * \text { (Radius, } \mathrm{m})\end{array}$ & $\begin{array}{c}\text { Rock } \\
\text { Description }\end{array}$ \\
\hline 1 & $\begin{array}{l}\text { Hong Kong } \\
\text { Island }\end{array}$ & $\begin{array}{l}\text { Happy Valley } \\
\text { Sports Ground }\end{array}$ & $\begin{array}{l}50 \mathrm{~m} / 22 \mathrm{~m} \\
\text { hexagonal }\end{array}$ & Granitic \\
\hline 2 & $\begin{array}{c}\text { New } \\
\text { Territories }\end{array}$ & $\begin{array}{c}\text { Tsing Yi Sports } \\
\text { Ground }\end{array}$ & $\begin{array}{l}41 \mathrm{~m} / 18 \mathrm{~m} \\
\text { hexagonal }\end{array}$ & Granitic \\
\hline 3 & $\begin{array}{l}\text { New } \\
\text { Territories }\end{array}$ & $\begin{array}{l}\text { Fung Kai No.1 } \\
\text { Secondary } \\
\text { School }\end{array}$ & $\begin{array}{c}50 \mathrm{~m} / 20 \mathrm{~m} \\
\text { hexagonal } 95 \mathrm{~m} / \\
30 \mathrm{~m} \text { triangular }\end{array}$ & Volcanic \\
\hline 4 & $\begin{array}{l}\text { New } \\
\text { Territories }\end{array}$ & Tseung Kwan O & $\begin{array}{l}48 \mathrm{~m} / 25 \mathrm{~m} \\
\text { hexagonal }\end{array}$ & Volcanic \\
\hline 5 & $\begin{array}{l}\text { New } \\
\text { Territories }\end{array}$ & $\begin{array}{l}\text { Yuen Long } \\
\text { Stadium }\end{array}$ & $\begin{array}{l}40 \mathrm{~m} / 18 \mathrm{~m} \\
\text { hexagonal }\end{array}$ & $\begin{array}{c}\text { Meta- } \\
\text { Sedimentary }\end{array}$ \\
\hline
\end{tabular}

* Examples of array configurations are shown in Fig. A2. 


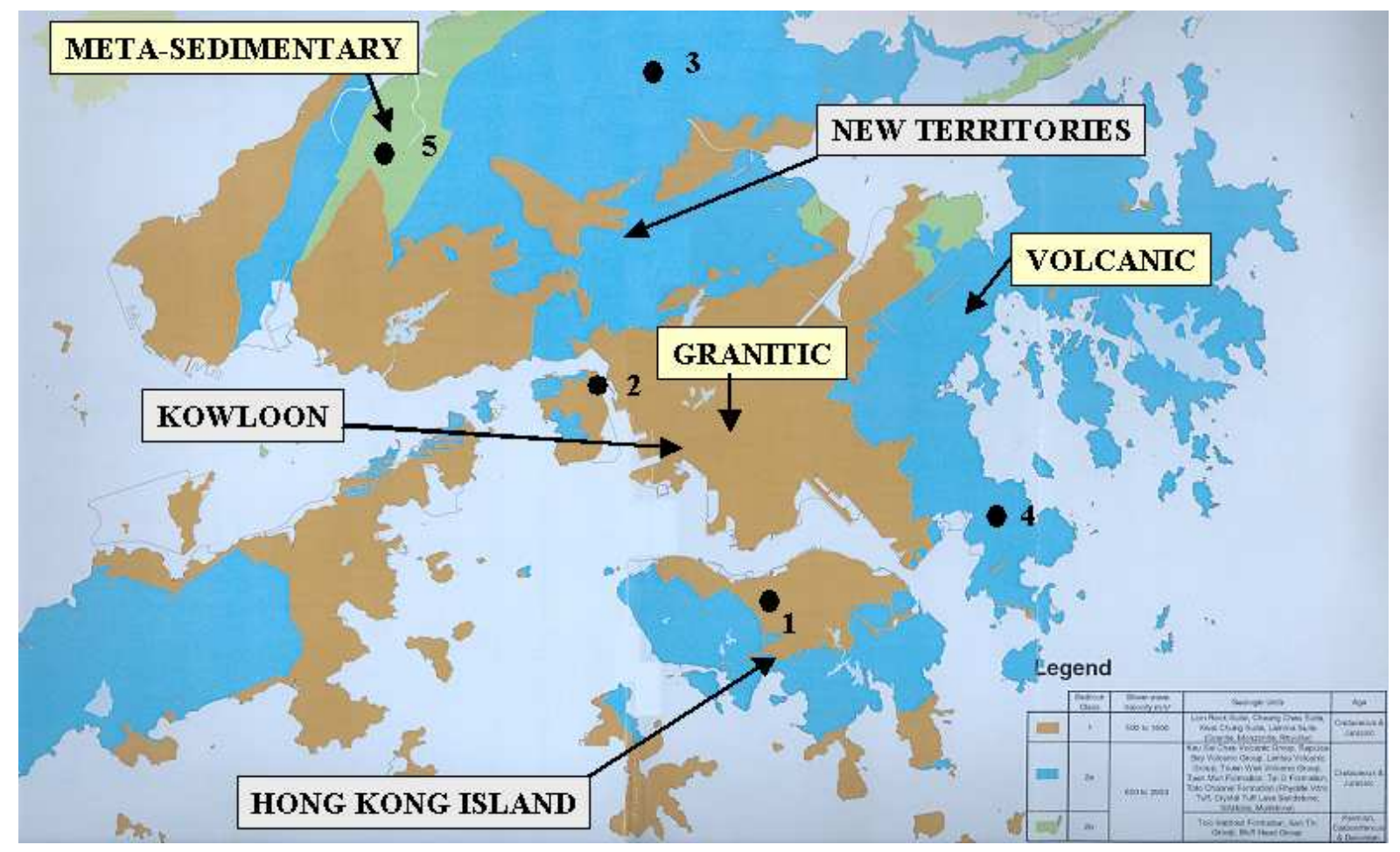

Fig. A1. Simplified geological map of Hong Kong and locations of SPAC surveys. 
(a)

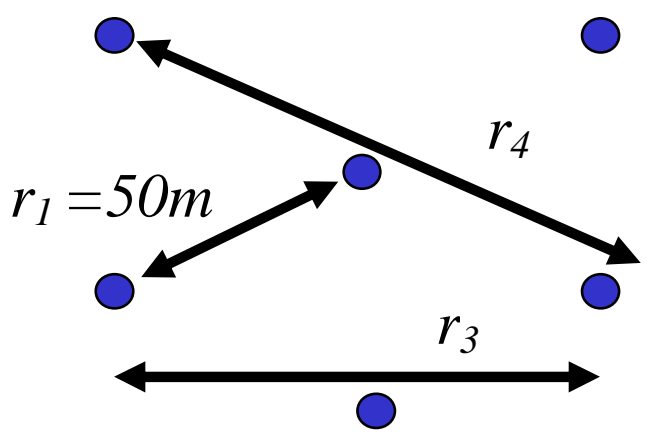

(b)

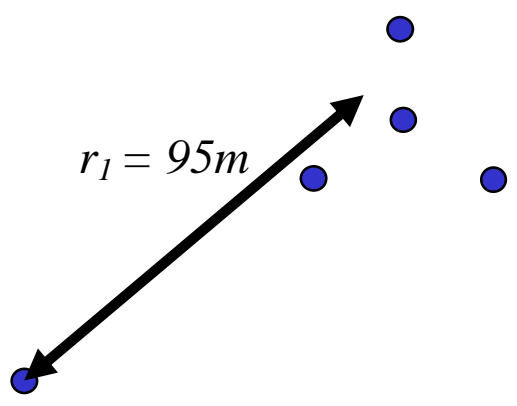

○

Fig. A2. $\quad$ Examples of SPAC array configurations employed in Hong Kong surveys:

(a) Hexagonal array with radius $=50 \mathrm{~m}$; (b) Triangular array with outer radius $=95 \mathrm{~m}$. 